Article

\title{
Recovery and Valorization of Bioactive and Functional Compounds from the Discarded of Opuntia ficus-indica (L.) Mill. Fruit Peel
}

\author{
Pierpaolo Scarano (D, Maria Tartaglia (D, Daniela Zuzolo (D), Antonello Prigioniero, Carmine Guarino *(D) \\ and Rosaria Sciarrillo
}

check for updates

Citation: Scarano, P.; Tartaglia, M.; Zuzolo, D.; Prigioniero, A.; Guarino, C.; Sciarrillo, R. Recovery and Valorization of Bioactive and Functional Compounds from the Discarded of Opuntia ficus-indica (L.) Mill. Fruit Peel. Agronomy 2022, 12, 388. https://doi.org/10.3390/ agronomy12020388

Academic Editor: Sung-Cheol Koh

Received: 29 December 2021

Accepted: 2 February 2022

Published: 4 February 2022

Publisher's Note: MDPI stays neutral with regard to jurisdictional claims in published maps and institutional affiliations.

Copyright: (c) 2022 by the authors. Licensee MDPI, Basel, Switzerland. This article is an open access article distributed under the terms and conditions of the Creative Commons Attribution (CC BY) license (https:// creativecommons.org/licenses/by/ $4.0 /)$.
Department of Science and Technology, University of Sannio, Via F. de Sanctis s.n.c., 82100 Benevento, Italy; scarano@unisannio.it (P.S.); mtartaglia@unisannio.it (M.T.); dzuzolo@unisannio.it (D.Z.); prigioniero@unisannio.it (A.P.); sciarril@unisannio.it (R.S.)

* Correspondence: guarino@unisannio.it; Tel.: +39-0824-305-156

\begin{abstract}
This work focused on the recovery and application of bioactive and functional compounds (BFC) from a waste matrix, the Opuntia ficus-indica (L.) Miller fruit peel (OFP), using different extraction methods: maceration and Extractor Naviglio ${ }^{\circledR}$. The presence of BFC was initially evaluated by following the extraction yields and antioxidant activity using the Folin-Ciocâlteu reagent and the DPPH method, respectively. The quali-quantitative content of BFC was also verified with UHPLC/UV-ESI-HRMS profile of OFP extracts. The evaluation of the BFC yields is aimed at using extract components, such as betanins, in the technological application as textile dye based on natural pigments: we evaluated the stability of the extracted dyes, tested the dyeing power and assessed the stability of the dye on the textile material. The results showed different compositions depending on the polarities of the solvents. The ethanol-water mixture extracts obtained using Naviglio method revealed an important presence in terms of total phenolic compound yields. Wool, linen and cotton fibers were chosen for the dyeing tests. Rock alum and lemon juice, two etching methods, were used. Results suggest that the OFP may be of great interest as a natural source of BFC for food, nutraceutical and technological applications in the sustainability context.
\end{abstract}

Keywords: Opuntia ficus-indica (L.) Mill.; sustainability; circular economy; secondary raw materials; peel; betanin; Extractor Naviglio

\section{Introduction}

The interest in the technological use of natural compounds for food, drink and textiles coloring [1,2] is certainly at the center of important debates, to address the eco-friendly future production of various sectors towards a more sustainable society. Nowadays, there is a growing awareness, also scientifically documented, about the environmental impacts of synthetic substances production and disposal [3,4]. Moreover, the massive waste production in our society is an increasing problem and innovative solutions must be found to recover it. It is well-known that $1 / 3$ of the total food is wasted during the food chain and those fruits and vegetables are the most wasted food item (FAO, 2011) In this context, the Sustainable Development Goals calls for halving per capita global food waste at retail and consumer levels by 2030, as well as reducing food losses along the production and supply chains. In addition, the improper handling of vegetal waste may pose a serious threat to the ecosystem and human health since they are not suitable for incineration due to their moisture content and associated with emission of greenhouse gases. Furthermore, considering vegetable discard as waste can often be considered a further loss since they have huge potential for obtaining functional compounds. With this mind, waste from agro-food chain are beginning to be identified as secondary raw materials (SRM), and their recovery offers multiple potential applications [5,6]. 
Nowadays consumers are increasingly paying attention to the use of natural compounds within edible products. Bioactive compounds that can be obtained from countless plant sources are well known for their antioxidant properties [7]. In recent times, more and more natural-based products with important biotechnological potential are being developed. From the food perspective, for example, the use of natural antioxidants facilitates the elimination of free radicals within the human body [8,9]. In addition, the food field, the use of natural adjuvants and colorings is becoming increasingly important within consumer products [10]. These products of natural origin or in any case functionalized with natural compounds, have gradually been introduced on the world market and have become important also in the treatment of chronic diseases [11,12].

At the same time, the recovery and use of natural dyes obtained from vegetable matrices understood as SRM, is of current interest. Although they are still a long way from replacing synthetic dyes, they are slowly finding wide use in line with the growing consumer appreciation for naturally based products $[7,13,14]$.

From this perspective, research into technological valuable bioactive compounds in SRM plays a key role in promoting increasingly sustainable production systems and human societies. In this context, the antioxidant properties of phenolic compounds contained in pear cactus plants, in particular from Opuntia ficus-indica (L.) Mill. [15] are of great interest. In the literature, $O$. ficus-indica products have already been described as an important food rich in compounds useful in protecting humans from degenerative diseases, such as cancer, diabetes and cardiovascular and gastric diseases [16,17].

Opuntia ficus-indica belongs to the family Cactaceae Juss., a family including 147 species [18] and about 1500 dicotyledonous angiosperm species. The genus Opuntia Mill. Includes 134 species whose bearing tends to be generally shrubby, low or creeping and rarely treelike. Opuntia species were native from American continent and later introduced worldwide (except northern Europe and north-central Asia) for commercial purposes [18,19].

O. ficus-indica was commonly defined as a tropical and subtropical plant, growing in arid and semi-arid climates [20]. The cactus O. ficus-indica (prickly pear or nopal cactus) is native to Mexico [18] and later spread to South America, Southern part of the United States of America, Africa, Eastern Australia, Indian subcontinent and Indochina, and Mediterranean region (USDA 2009) [18,21]. In folk medicine, the cactus is cultivated and used as a medicinal plant in many dozens of countries, but it is also traditionally considered a toxic weed in some regions, such as Australia and South Africa. In many other countries, it is considered an alternative or back-up diet during periods of drought because cacti remain succulent and fresh for longer periods.

This species has gradually attained economic importance in agriculture sector and is the most important economic cactus species worldwide [22,23]. It is known that the disposal of $O$. ficus-indica wastes is a problem for environmental pollution due to fermentation phenomena [24,25]. All the above add a dimension for the exploitation of SRM derived by $O$. ficus-indica by using advanced technologies to recover specific molecules that can be employed, once extracted [26,27].

Currently, solvent extraction of bioactive compounds from plant materials is a key step in the production of products rich in technologically viable compounds at industrial level (both in food and other sectors, such as textiles). In obtaining these technologically valuable compounds (dyes, stabilizers, antioxidants, antiradicals, etc.) [28], in addition to the importance of the solvent [29], the use of new technologies and methodologies for extraction is of paramount importance. New-generation techniques, such as the Extractor Naviglio ${ }^{\circledR}$ [30], which is a technique suited to solid-liquid extraction in the field of bioactive molecules, better support the obtaining of such molecules because they preserve their biotechnological and technological contribution. Fortunately, solid-liquid extractions, such as maceration, already allowed most of the molecules present in the solid matrix (plant, tissue, etc.) to transfer and solubilize in the extracting liquid, based on diffusion and osmosis phenomena [31]. After extraction, given the fact that bioactive compounds are often the minority component, reasoning on the dry weight of the whole plant matrix that 
is considered, an additional purification and/or concentration process may be required before characterizing the compounds contained in crude extracts to guide the formulation of technologically sustainable products.

The possibility of recovering high value-added by-products from SRM with highly performing techniques is fundamental to reduce crop management costs and offer new income strategies within the agri-food chain. This approach could trace the way toward a more sustainable agri-food system, bringing great advantages from the point of view of circular economy. Based on these premises, the aim and objective of our work was to investigate the possible industrial waste of O. ficus-indica (such as the epicarp commonly called peel, now abbreviated OFP) (i) evaluating the bioactive compounds with particular attention to the presence of phenolic ones and (ii) exploring the possible technological application such as the coloration of textile fibers.

\section{Materials and Methods}

\subsection{Chemicals and Solvents}

Solvents and reagents were purchased from the commercial sources listed below. All of these are of high purity grade and used as received unless otherwise specified. Ethanol $96 \%$ Analytical Grade Reagents (or RPE) for analysis and hydrochloric acid 37\% RPE for analysis, methanol for HPLC and pure sodium chloride were purchased from Sigma-Aldrich Chemical Company (Milan, Italy). Aluminum potassium sulphate dodecahydrate was purchased from Sigma-Aldrich Chemical Company (Milan, Italy). Potassium bicarbonate, anhydrous sodium carbonate for analysis and gallic acid ACS for analysis were obtained from Carlo Erba (Milan, Italy). Hypergrade acetonitrile for LC-MS was purchased from Merck Millipore $\mathrm{GmbH}$ (Milan, Italy). Absolute ethanol for reactions was purchased from VWR Chemicals (Fontenay-sous-Bois, France). Sodium hydroxide pellets and anhydrous sodium sulphate, both reagent grade, are from Scharlau and obtained from Scharlab S.L. (Sentmenat, Spain). 2,2-Diphenyl-1-picrylhydrazyl (free radical) was obtained from Alfa Aesar company Thermo Fisher Scientific (Rodano, Milan, Italy). All analytical standards, such as gallic acid, citric acid, kaempferol, betanin, vulgaxanthin and isorhamnetin, were obtained from Sigma-Aldrich Chemical Company (Milan, Italy).

Double distilled water was used for the preparation of the solutions. Extracts obtained from peels of O. ficus-indica (OFP) were applied without any purification. Stock solutions of OFP were prepared by diluting them in water or in a hydroalcoholic solution.

\subsection{Plant Materials}

Prickly pears were collected from farms in Sicily, from Roccapalumba (Palermo,

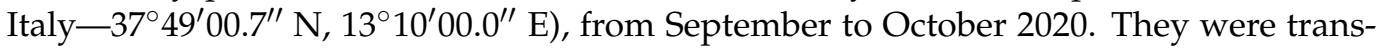
ported in vacuum-sealed polyethylene bags and stored in refrigerated boxes at $-4{ }^{\circ} \mathrm{C}$; samples were transported to the laboratory within a maximum of $5 \mathrm{~h}$ after harvest. Subsequently, the fruits were washed thoroughly with distilled water to remove impurities and spines. The fruits were peeled and the peel, pulp, mucilage and seed parts were separated and stored separately, and stored at $-24{ }^{\circ} \mathrm{C}$ until use.

\subsection{Preparation of Fruit Peel Extracts}

The sample to solvent ratio was kept constant (plant material:solvent $=1: 10)$ for the two methods of extraction and for all experiments.

The fruit peel of O. ficus-indica (henceforth referred to as O. ficus-indica fruit peel extracts, OFP, or simply as extracts), were extracted by two different extraction methods; moreover, two different pure solvents and a mix of them were used: ethanol $(\mathrm{EtOH})$, bidistilled water $\left(\mathrm{H}_{2} \mathrm{O}\right)$ and a solution of EtOH and $\mathrm{H}_{2} \mathrm{O}$ in a ratio of 8:2 (v:v). Extractions were conducted at room temperature at different times: $2 \mathrm{~h}, 4 \mathrm{~h}, 8 \mathrm{~h}, 12 \mathrm{~h}$ and $24 \mathrm{~h}$. 


\subsection{Maceration Extraction (ME)}

Ten grams of prickly pear peels were used for each extraction. These samples were extracted by maceration with $100 \mathrm{~mL}$ of absolute $\mathrm{EtOH}$, bidistilled $\mathrm{H}_{2} \mathrm{O}$ and EtOH: $\mathrm{H}_{2} \mathrm{O}$ mixture (8:2 ratio, $v: v)$ under continuous stirring (obtaining on the stirring plate at $750 \mathrm{rpm}$ with a magnetic stir bar), under controlled nitrogen atmosphere and in the dark, for $24 \mathrm{~h}$. During the extraction, samples were taken at $2 \mathrm{~h}, 4 \mathrm{~h}, 8 \mathrm{~h}$ and $12 \mathrm{~h}$, After maceration, the peel extracts were filtered through paper to remove any floating matter. The clear extract solutions obtained were stored in a dark container, at $-24{ }^{\circ} \mathrm{C}$, until their use (within a maximum of 2 days).

\subsection{Extractor Naviglio ${ }^{\circledR}$ Extraction (NE)}

The extraction was then repeated on another sample prickly pear peels using Extractor Naviglio ${ }^{\circledR}$. Extractor Naviglio ${ }^{\circledR}$ (ATLAS FILTRI ITALIA, Limena, Padova, Italy) represents an eco-innovative technological solution in solid-liquid extraction. This extraction is carried out by the discovery of a new principle of solid-liquid extraction, called "Principio di Naviglio" (Naviglio's Principle) [30]. The Extractor Naviglio ${ }^{\circledR}$ bases its extraction principle on a suction effect, due to the application inside the machine of a pressure of approximately 9-10 bar for specific time steps, which are defined as cycles, within which each compression is followed by an immediate decompression to atmospheric pressure. Each extraction cycle comprises a phase known as the 'static phase' followed by a phase known as the 'dynamic phase'. During the static phase, the system (and therefore the stressed matrix being extracted together with the solvent used) is subjected to pressure for a certain time (determined by the operator based on the composition of the solid matrix from which the molecules are to be extracted): in this phase the solvent penetrates into the matrix and permeates all the empty spaces, crossing the cell membranes of the plants more effectively than extraction by maceration. At the end of the static phase, the dynamic phase begins. It aims both to generate a negative pressure gradient between the inside and the outside of the solid matrix, which represents the effective dragging principle of the extraction (Naviglio's Principle), and the remixing of the liquid throughout the system to avoid the formation of zones with different concentrations of extracted substances near the surface of the solid matrix.

A quantity of $60 \mathrm{~g}$ of sample was placed in a $50.0 \mu \mathrm{m}$ filtering membrane bag and placed into the $500.0 \mathrm{~mL}$ chamber of Extractor Naviglio ${ }^{\circledR}$ (the volume of solvent used for the extraction is $600.0 \mathrm{~mL}$ as the fittings must also be considered). Then the chamber was filled with solvent. The three extractions were carried out under the same conditions of ME: with absolute EtOH, bidistilled $\mathrm{H}_{2} \mathrm{O}$ and EtOH: $\mathrm{H}_{2} \mathrm{O}$ mixture (8:2 ratio, v:v). Each extraction cycle consisted of a 2 min static phase, followed by a 2 min dynamic phase; the total number of cycles was 360 for a total time of $24 \mathrm{~h}$. During the extraction, solution samples were taken at $2 \mathrm{~h}, 4 \mathrm{~h}, 8 \mathrm{~h}$ and $12 \mathrm{~h}$. After filtration, the clear extract solutions obtained were stored in a dark container, at $-24{ }^{\circ} \mathrm{C}$, until their use (within a maximum of 2 days).

\subsection{Soluble Solid Contents and $\mathrm{pH}$}

Soluble solid content $\left({ }^{\circ} \mathrm{Bx}\right)$ and $\mathrm{pH}$ were measured in all extracts by means of a refractometer and Metrohm $\mathrm{pH}$ meter.

A Metrohm $827 \mathrm{pH}$ meter, a two-channel laboratory $\mathrm{pH}$ measuring instrument for measuring $\mathrm{pH} / \mathrm{mV}$ and temperature, was used for the $\mathrm{pH}$ measurement.

Specific gravities were measured with a Brix and Gravity Refractometer with automatic temperature compensation (ATC) that features a 0-32\% Brix Scale and a Specific Gravity Scale from 1.000-1.130.

\subsection{Total Phenolic Compound Content (TPC)}

All absorbance measurements were carried out using a Varian Cary 50 UV/Vis spectrophotometer. A $1.0 \mathrm{~cm}$ long optical path glass cell was used in all measurements. 
Total phenolic compound content was measured according to the Folin-Ciocalteu reagent method developed by Dewanto et al. [32]. Briefly, $5.0 \mu \mathrm{L}$ of sample extract were added to a glass test tube. A quantity of $120 \mu \mathrm{L}$ of a methanol and bidistilled water solution in a ratio of 80:20. $125 \mu \mathrm{L}$ of Folin-Ciocâlteu reagent and $1.25 \mathrm{~mL}$ of $\mathrm{Na}_{2} \mathrm{CO}_{3}$ $(7.5 \% \mathrm{w} / \mathrm{v})$ were added, and the solution was mixed and allowed to stand for $90 \mathrm{~min}$ at room temperature. Then, absorbance at $760 \mathrm{~nm}$ was measured, and the total phenolic

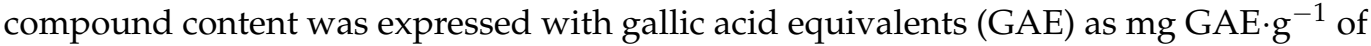
extract solution with a calibration curve built using $80,100,200,300$ and $400 \mathrm{mg} \cdot \mathrm{L}^{-1}$ of gallic acid, respectively, and calculated as a mean value $\pm \operatorname{SD}(n=3)$.

\subsection{Scavenging Activity for 1.1-Diphenyl-2-picrylhydrazyl (DPPH) Radical}

In the present experiment, the radical scavenging activity of some extracts was estimated using the DPPH assay following the method developed by Mosquera et al. [33].

A $1 \mathrm{mM}$ Trolox solution in methanol (concentration range from 0.01 to $0.20 \mathrm{mM}$ ) was used as the reference standard for the construction of the calibration line. The results are expressed in terms of inhibition I of the radical DPPH solution (defined precisely as inhibition), $\mathrm{IC}_{50}$ value (i.e., efficient concentration also defined as $\mathrm{EC}_{50}$ ) or the concentration in $\mathrm{mM}$ of the substance that causes the loss of $50 \%$ of the activity of the oxidant: the lower the value of the $\mathrm{IC}_{50} \%$ parameter, the greater the antioxidant activity of the sample. The percentage inhibition calculation was calculated according to the following equation:

$$
I \%=\left[\frac{\left(A_{\text {control }}-A_{\text {sample }}\right)}{A_{D P P H}}\right] \times 100,
$$

where $A_{\text {sample}}, A_{\text {control }}$ and $A_{\mathrm{DPPH}}$ are the absorbance of the sample, absorbance of the control and absorbance of the DPPH solution, respectively.

\subsection{Extract Purifications}

In order to purify the compounds with antioxidant action obtained through the different extractions conducted, a liquid-liquid extraction protocol was performed through separating funnel. The extractions have foreseen the use in sequence and with more repetitions of washing carried out with solvents with increasing polarity. Hexane, chloroform and 1-butanol have been used as solvents. At least three washes were carried out with each of the above solvents in a 1:1 (v:v) ratio with the sample solution. Three sub-fractions were obtained for each initial sample. The three fractions, the water residues and the mother sample solutions are analyzed by UHPLC/UV-ESI-HRMS analysis.

\subsection{UHPLC/UV-ESI-HRMS Analysis Conditions}

Sample analyses were performed with UHPLC/UV-ESI-HRMS and a Dionex Ultimate 3000 RS, Thermo Scientific (Rodano, Milan, Italy), equipped with a Hypersil Gold C18 column $(100 \times 2.1 \mathrm{~mm}, 1.9 \mu \mathrm{m}$ particle size, Thermo Scientific $)$, coupled to a Q-ExactiveTM high resolution mass spectrometer (Thermo Scientific, Rodano, Milan, Italy).

The extract samples were solubilized in methanol to obtain a final concentration of $10 \mathrm{mg} \cdot \mathrm{mL}^{-1}$. A known aliquot of internal standard (gallic acid) was added to each extract such as to have a concentration of $50 \mathrm{mg} \cdot \mathrm{L}^{-1}$ in the final solution.

The chromatographic column, Hypersil Gold C18 column $(100 \times 2.1 \mathrm{~mm}, 1.9 \mu \mathrm{m}$ particle size, was equilibrated in $98 \%$ of solvent A (aqueous solution of $0.1 \%$ formic acid) and $2 \%$ of solvent B (methanol). Column flow was maintained at $300 \mu \mathrm{L} \cdot \mathrm{min}^{-1}$ and solvent $\mathrm{B}$ concentration was increased linearly from $2 \%$ to $23 \%$ in $6 \mathrm{~min}$, remains in isocratic for $5 \mathrm{~min}$, then linearly increased from $23 \%$ to $50 \%$ in $7 \mathrm{~min}$, and from $50 \%$ to $98 \%$ in $5 \mathrm{~min}$, remains in isocratic for $6 \mathrm{~min}$ and finally returns to $2 \%$ in $6 \mathrm{~min}$, remaining in isocratic for $3 \mathrm{~min}$. The UV-vis detector is set at 235, 330, 480 and $535 \mathrm{~nm}$. Volume of sample injected: $5 \mu \mathrm{L}$. For the mass analysis the electrospray (ESI) was selected in both negative and positive polarity, with the following operating conditions: resolution, 70,000 (FWHM 
at $200 \mathrm{~m} / \mathrm{z})$, IT $100 \mathrm{~ms}$, and ACG target $=1 \cdot 10^{6}$, Scan range $(100-100 \mathrm{~m} / \mathrm{z})$. In each scan, the most intense precursors were automatically selected by the instrument and MS/MS analysis was performed on them with the following operating conditions: resolution: 35,000; AGC target = 1.105; maximum IT 200 ms; collision energy (stepped NCE): 25, 30, 40 . The quadrupole isolation window was set to $1.6 \mathrm{~m} / \mathrm{z}$. The instrument was calibrated prior to each run using Thermo Scientific supplied calibration solution.

For the preparation of the analyzed samples, $10.0 \mathrm{mg}$ of sample are weighed and solubilized in $1.0 \mathrm{~mL}$ divided as follows: $900 \mu \mathrm{L}$ of methanol and $100 \mu \mathrm{L}$ of a solution of gallic acid (internal standard) with a concentration of $500 \mathrm{ppm}$ in methanol. The samples tested are listed in Table 3.

For some samples, specifically for the OPHOM, OPHOR, OPEHM, OPEHR (OP $=0$. ficus-indica peel extract samples; $\mathrm{HO}=$ extract in bidistilled and deionized $\mathrm{H}_{2} \mathrm{O} ; \mathrm{ET}=$ extract in absolute $\mathrm{EtOH} ; \mathrm{EH}=$ extract in solution mixture of $\mathrm{EtOH}: \mathrm{H}_{2} \mathrm{O}(8: 2$ ratio, v:v)) samples, a $5 \%$ of dimethysulphoxide was used to facilitate solubilization. The characterization tables that will be shown below show analysis carried out both in negative and positive polarity for the different samples. The quantification was carried out, for all the samples, in negative polarity by using an internal standard solution corresponding to gallic acid with a concentration equal to $50 \mathrm{ppm}$ in methanol with a retention time of $3.20 \mathrm{~min}$ and an m/z equal to $169.0134[\mathrm{MH}]^{-}$. The percentages shown in the table of the different analytes are expressed as a weight/weight percentage $(\% w / w)$ with respect to the weight of the dry extract expressed in Table 4.

\subsection{Dyeing Different Fiber Discs with Dye Extract}

The fibers selected for the study were cotton, wool and linen. Discs of fabric (Figure 1) with a diameter of $7.5 \mathrm{~cm}$ were prepared from the available fibers in order to have a comparison parameter per unit area. All surface area and weight parameters were collected. The methodology applied followed the work adopted by Scarano et al. [34]. In addition to the reported method, tissues were drained and dried and, subsequently, were washed twice (for approximately $2 \mathrm{~min}$ ) at $40{ }^{\circ} \mathrm{C}$ with distilled water. The staining and washing process was repeated 3 times. Uncolored fiber samples were used as controls. The experiments were performed in triplicate.

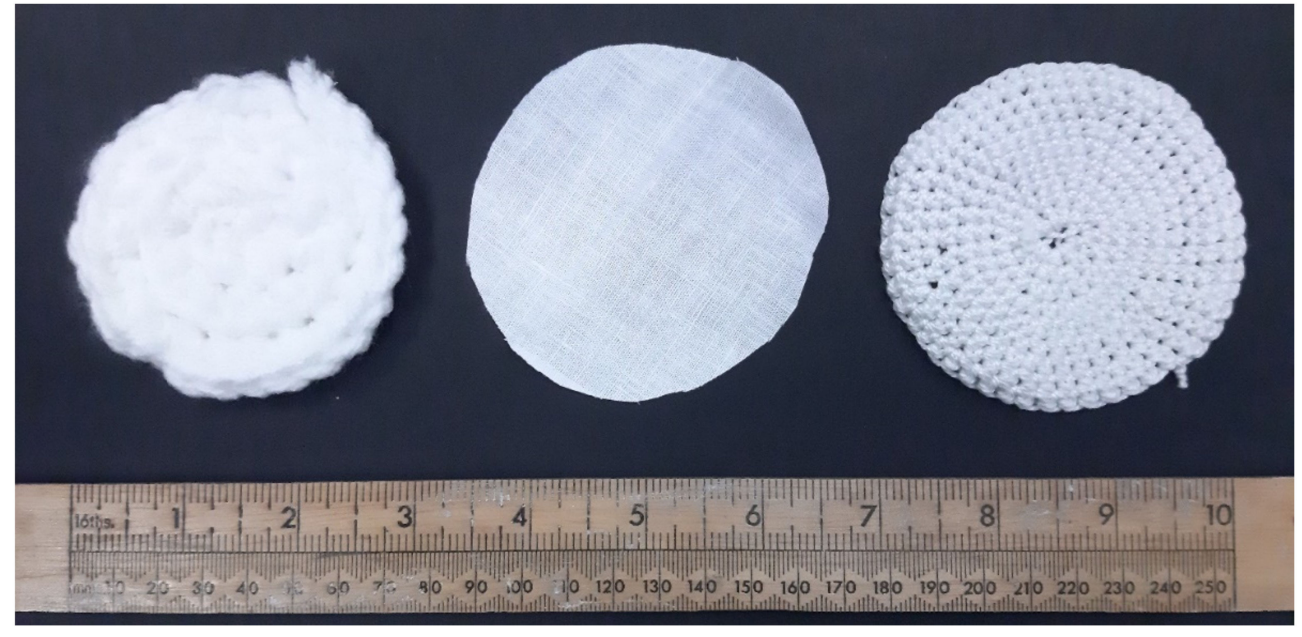

Figure 1. Image of discs wool (left), linen (center) and cotton (right) fibers before staining and dyeing treatments.

Extracts rich in dye molecules, corresponding to the purified OPHOR, OPETR and OPEHR (see Table 3) extracts (all in aqueous solvent), were mixed to obtain a single dye solution with which to color the different fiber samples. 


\subsection{Colorimetric and Fastness Properties of Different Fiber Discs Dyed with Dye Extract}

Tissues dyed with the dye extracts discussed in this study were subjected to color reflectance measurements using an FRU WR-10 QC colorimeter from ShenZhen Wave Optoeletronics Technology with an observation area of $4 \mathrm{~mm}$ in diameter. Measurements were made using the method reported in the work of Chan-Bacab et al. [35], which reports the method for fiber coloration analysis using CIELAB standards [36]. The following measurement conditions were selected: light source D65 (representing a daylight phase), a correlated color temperature (CCT) between $5000-6500 \mathrm{~K}$, and standard observer CIE $10^{\circ}$.

The wool, linen and cotton fibers ed with the dye extract were subjected to colorimetric measurement and the color measurement parameters, $\mathrm{L}^{*}, \mathrm{a}^{*}, \mathrm{~b}^{*}, \mathrm{C}^{*} \mathrm{ab}$ and $\mathrm{h}_{\mathrm{ab}}$, were recorded according to the CIELAB color system and expressed in CIELAB coordinates (Supplementary Figure S16, without measurement units). As verified by practice and literature [27], the minimum number of measurements required to characterize these parameters in each sample of colored textile material. Eight measurements were taken to characterize an area of approximately $7.50 \mathrm{~cm}$ in diameter, with a reading aperture diameter of $4 \mathrm{~mm}$. The minimum reading parameter was defined by the fixed section of the inverted exponential decay plot, obtained from the CIELAB color coordinates $\left(\mathrm{L}^{*}, \mathrm{a}^{*}\right.$ and $\left.\mathrm{b}^{*}\right)$ versus the number of measurements.

One-way analysis of variance (ANOVA) was used to determine whether there was statistically significant difference between the treatment (U, DWM, DPL and DPA) in terms of CIELAB color coordinates $\left(\mathrm{L}^{*}, \mathrm{a}^{*}, \mathrm{~b}^{*}, \mathrm{C}^{*} \mathrm{ab}\right.$ and $\left.\mathrm{h}_{\mathrm{ab}}\right)$. Tukey post-hoc $(p<0.01)$ was used to determine which specific treatment differed from each other.

\subsection{Data Analyses}

Data were presented as mean (triplicate measures) and standard deviation (SD). Oneway analysis of variance (ANOVA) was conducted to test differences between extraction methods (maceration and Extractor Naviglio ${ }^{\circledR}$ ). One-way analysis of variance (ANOVA) was also used to determine whether there were statistically significant differences between the treatment (U, DWM, DPL and DPA) in terms of CIELAB color coordinates $\left(\mathrm{L}^{*}, \mathrm{a}^{*}, \mathrm{~b}^{*}\right.$, $\mathrm{C}^{*}{ }_{\mathrm{ab}}$ and $\left.\mathrm{h}_{\mathrm{ab}}\right)$. Tukey post-hoc $(p<0.01)$ was used to determine which specific treatment differed from each other.

\section{Results}

\subsection{Parameters of the Extracts}

Different parameters of the extracts obtained with the different extraction techniques were measured. The values of $\mathrm{pH}$, specific gravities and dry residue were collected for all extracts at $24 \mathrm{~h}$. This is the representative sample on which the subsequent analyses were performed. The values obtained for the other incremental extraction times $(2,4,8,12 \mathrm{~h})$ showed no significant differences compared to the extraction at $24 \mathrm{~h}$. The values are shown in Table 1 and discussed in Section 4.1.

Table 1. $\mathrm{pH}$, specific gravity and dry residue of the different OFP extracts at $24 \mathrm{~h}$. Values are presented as mean (triplicate) $\pm \mathrm{SD}$. Different letters indicate significant differences between methods parameters at $p<0.05$.

\begin{tabular}{|c|c|c|c|c|c|c|}
\hline \multirow{2}{*}{ Solvent } & \multicolumn{3}{|c|}{ Maceration Method } & \multicolumn{3}{|c|}{ Extractor Naviglio ${ }^{\circledR}$ Method } \\
\hline & $\mathrm{pH}$ & $\begin{array}{c}\text { Brix } \\
{\left[{ }^{\circ} \mathbf{B x}\right]}\end{array}$ & $\begin{array}{c}\text { Residue } \\
\left(\mathrm{g} \cdot \mathrm{L}^{-1}\right)\end{array}$ & pH & $\begin{array}{c}\text { Brix } \\
{\left[{ }^{\circ} \mathbf{B x}\right]}\end{array}$ & $\begin{array}{c}\text { Residue } \\
\left(\mathrm{g} \cdot \mathrm{L}^{-1}\right)\end{array}$ \\
\hline $\mathrm{H}_{2} \mathrm{O}$ & $6.67 \pm 0.02^{a}$ & $0.8 \pm 0.1^{\mathrm{a}}$ & $7.72 \pm 0.04^{\mathrm{a}}$ & $6.44 \pm 0.01^{\mathrm{a}}$ & $0.8 \pm 0.1^{\mathrm{a}}$ & $5.32 \pm 0.01^{b}$ \\
\hline $\mathrm{EtOH}$ & $6.73 \pm 0.01^{a}$ & $1.3 \pm 0.1^{\mathrm{a}}$ & $7.14 \pm 0.02^{a}$ & $6.74 \pm 0.03^{a}$ & $1.0 \pm 0.1^{\mathrm{a}}$ & $7.84 \pm 0.01^{a}$ \\
\hline EtOH: $\mathrm{H}_{2} \mathrm{O}(8: 2)$ & $6.71 \pm 0.01^{\mathrm{a}}$ & $1.2 \pm 0.1^{\mathrm{a}}$ & $9.86 \pm 0.12^{\mathrm{a}}$ & $6.84 \pm 0.02^{\mathrm{a}}$ & $1.0 \pm 0.1^{\mathrm{a}}$ & $5.16 \pm 0.03^{b}$ \\
\hline
\end{tabular}

$\mathrm{pH}$ and ${ }^{\circ} \mathrm{Bx}$ seems to be kept constant in both extraction methods and for all solvents used. Regarding dry residue, for the same amount of matrix used and volume of 
solvent employed, differences occur between the two extraction methods when $\mathrm{H}_{2} \mathrm{O}$ and EtOH: $\mathrm{H}_{2} \mathrm{O}(8: 2)$ solvents are used.

\subsection{Polyphenolic Content}

The TPC of the different OPF extracts (Table 2) show higher values for EtOH and EtOH: $\mathrm{H}_{2} \mathrm{O}(8: 2)$ solvents in both extraction methods. However, significant differences $(p<0.05)$ are found between ME and NE for TPC yield in the EtOH: $\mathrm{H}_{2} \mathrm{O}(8: 2)$ mixture (Table 2).

Table 2. Total phenolic compound content (TPC) of the different OFP extracts (expressed in $\mathrm{mg}$ $\mathrm{GAE} \cdot \mathrm{g}^{-1}$ extract). Values are presented as mean (triplicate) $\pm \mathrm{SD}$. Different superscripts letters indicate significant differences between methods parameters at $p<0.05$.

\begin{tabular}{|c|c|c|c|c|c|c|}
\hline \multirow[b]{2}{*}{$\begin{array}{l}\text { Extraction } \\
\text { Time (h) }\end{array}$} & \multicolumn{3}{|c|}{ Maceration Method } & \multicolumn{3}{|c|}{ Extractor Naviglio ${ }^{\circledR}$ Method } \\
\hline & $\mathrm{H}_{2} \mathrm{O}$ & EtOH & $\begin{array}{c}\text { EtOH: } \mathrm{H}_{2} \mathrm{O} \\
(8: 2)\end{array}$ & $\mathrm{H}_{2} \mathrm{O}$ & EtOH & $\begin{array}{c}\text { EtOH: } \mathrm{H}_{2} \mathrm{O} \\
(8: 2)\end{array}$ \\
\hline 2 & $6.19 \pm 0.01^{\mathrm{a}}$ & $21.13 \pm 0.05^{\mathrm{a}}$ & $22.14 \pm 0.58^{\mathrm{a}}$ & $8.80 \pm 0.01^{b}$ & $21.01 \pm 0.76^{\mathrm{a}}$ & $30.38 \pm 0.02^{b}$ \\
\hline 4 & $6.54 \pm 0.07^{\mathrm{a}}$ & $22.03 \pm 0.21^{\mathrm{a}}$ & $22.57 \pm 0.01^{\mathrm{a}}$ & $9.01 \pm 0.002^{b}$ & $21.82 \pm 0.07^{\mathrm{a}}$ & $30.51 \pm 0.22^{b}$ \\
\hline 8 & $7.21 \pm 0.11^{\mathrm{a}}$ & $22.44 \pm 0.002^{\mathrm{a}}$ & $24.25 \pm 0.004^{\mathrm{a}}$ & $9.94 \pm 0.03^{b}$ & $23.14 \pm 1.09^{\mathrm{a}}$ & $33.28 \pm 0.14^{b}$ \\
\hline 12 & $7.68 \pm 0.01^{\mathrm{a}}$ & $24.65 \pm 0.04^{\mathrm{a}}$ & $25.93 \pm 0.17^{\mathrm{a}}$ & $10.27 \pm 0.07^{b}$ & $24.86 \pm 0.23^{\mathrm{a}}$ & $35.05 \pm 0.09^{b}$ \\
\hline 24 & $7.84 \pm 0.003^{\mathrm{a}}$ & $25.15 \pm 0.02^{a}$ & $26.36 \pm 0.01^{\mathrm{a}}$ & $10.48 \pm 0.01^{b}$ & $25.37 \pm 0.004^{\mathrm{a}}$ & $36.17 \pm 0.003^{b}$ \\
\hline
\end{tabular}

$\mathrm{GAE}=$ gallic acid equivalent.

The data show that as extraction time increases, there is an increase in TPC for both methods.

\subsection{Radical Scavenging Activity}

The use of the DPPH method for measuring radical scavenging activity of any antioxidant is a rapid, reliable and reproducible method for detecting in vitro antioxidants of plant extracts and pure compounds $[12,26]$. The values obtained for the other incremental extraction times $(2,4,8,12 \mathrm{~h})$ showed no significant differences compared to the extraction at $24 \mathrm{~h}$. Therefore, only the $24 \mathrm{~h}$ extracts were subjected to analysis. DPPH radical scavenging activity of the different $O$. ficus-indica fruit peel extracts was expressed as I\% and results as reported as mean values of experiments conducted in triplicate $( \pm \mathrm{SD})$. As for the samples obtained using the ME method, the best result was obtained for samples extracted in EtOH: $\mathrm{H}_{2} \mathrm{O}(8: 2)$ with $18.53 \pm 1.28$, followed by those in $\mathrm{H}_{2} \mathrm{O}$ with $17.31 \pm 1.73$ and in $\mathrm{EtOH}$ with $13.44 \pm 0.73$. As for the samples obtained by NE method, the best result was obtained for the samples extracted in $\mathrm{H}_{2} \mathrm{O}$ with $13.58 \pm 1.88$, followed by those in $\mathrm{EtOH}: \mathrm{H}_{2} \mathrm{O}(8: 2)$ with $12.09 \pm 0.68$ and in $\mathrm{EtOH}$ with $10.83 \pm 0.58$. All results have been reported graphically in Figure 2.

\subsection{Extract Purification}

Given that the extracts obtained through NE method were found to be more performing in at least two of the three analysis methods used previously (dry residue, TPC and I\%), it was decided to subject these samples to UHPLC/UV-ESI-HRMS analysis. The analyzed samples are shown in Table 3.

Table 4 shows the betanin quantification that are expressed in terms of percentages given in the table for the different samples as a percentage by weight $(\% w / w)$ of the weight of the dry extract. 


\section{DPPH radical scavenging activity (\%)}

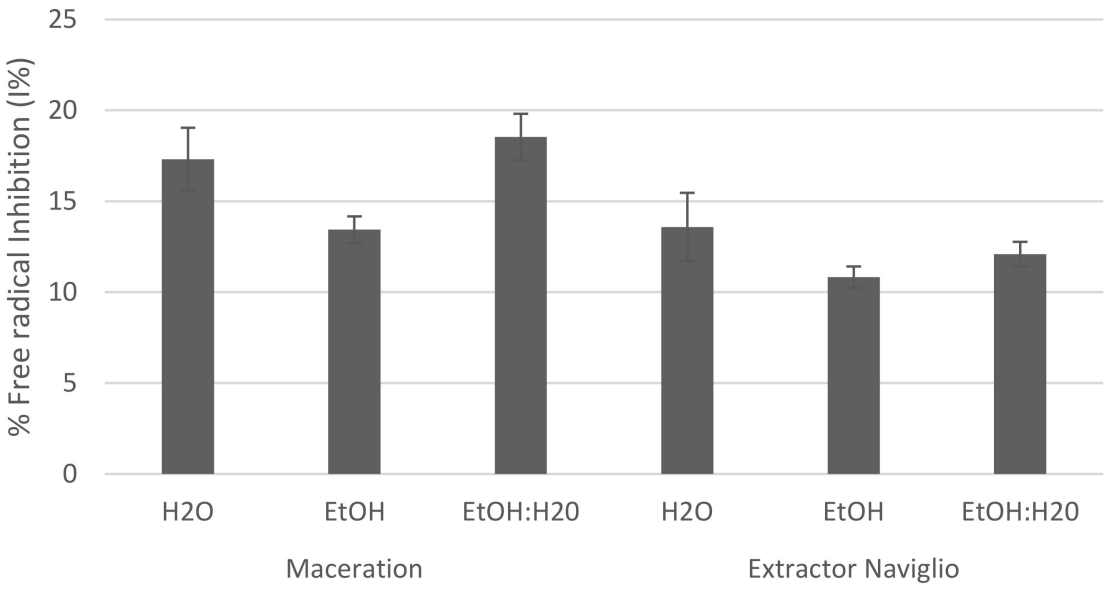

Figure 2. DPPH radical scavenging activity of OFP extracts by ME and NE methods with different solvents. The results are expressed as '\% free radical inhibition $(\mathrm{I} \%)^{\prime}$.

Table 3. OFP extract samples subjected to UHPLC/UV-ESI-HRMS analysis.

\begin{tabular}{|c|c|c|}
\hline Sample ID & Extraction Solvent & Purification/Solubilization Solvent \\
\hline OPHOM & $\mathrm{H}_{2} \mathrm{O}$ & Mother solution * \\
\hline OPHOE & " & Hexane \\
\hline OPHOC & “ & Chloroform \\
\hline OPHOB & “ & Butanol \\
\hline OPHOR & " & Water residue \\
\hline OPETM & $\mathrm{EtOH}$ & Mother solution * \\
\hline OPETE & “ & Hexane \\
\hline OPETC & “ & Chloroform \\
\hline OPETB & “ & Butanol \\
\hline OPETR & “ & Water residue \\
\hline OPEHM & EtOH: $\mathrm{H}_{2} \mathrm{O}(8: 2)$ & Mother solution * \\
\hline OPEHE & " & Hexane \\
\hline OPEHC & “ & Chloroform \\
\hline OPEHB & “ & Butanol \\
\hline OPEHR & " & Water residue \\
\hline OPHOM & 3.69 & \\
\hline OPHOE & n.q. & \\
\hline \multicolumn{3}{|c|}{$\begin{array}{l}\text { *All samples of extracts are resolubilized in bidistilled } \mathrm{H}_{2} \mathrm{O} \text { at } 2 \% \text { of absolute } \mathrm{EtOH} \text {, this represents the "Moth } \\
\text { solution". OP }=O \text {. ficus-indica peel extract samples. } \mathrm{HO}=\text { extract in bidistilled and deionized } \mathrm{H}_{2} \mathrm{O} . \mathrm{ET}=\text { extract } \\
\text { absolute EtOH. } \mathrm{EH}=\text { extract in solution mixture of } \mathrm{EtOH}: \mathrm{H}_{2} \mathrm{O}(8: 2 \text { ratio, v:v). }\end{array}$} \\
\hline \multicolumn{2}{|c|}{ Sample ID } & Quantification (\%w/w) \\
\hline \multicolumn{2}{|c|}{ OPHOC } & n.q. \\
\hline \multicolumn{2}{|c|}{ OРНOB } & 0.18 \\
\hline \multicolumn{2}{|c|}{ OPHOR } & 3.46 \\
\hline \multicolumn{2}{|c|}{ OPETM } & 3.00 \\
\hline \multicolumn{2}{|c|}{ OPETE } & n.q. \\
\hline \multicolumn{2}{|c|}{ OPETC } & n.q. \\
\hline \multicolumn{2}{|c|}{ OPETB } & 0.17 \\
\hline \multicolumn{2}{|c|}{ OPETR } & 2.73 \\
\hline \multicolumn{2}{|c|}{ OPEHM } & 5.04 \\
\hline
\end{tabular}


Table 4. Cont.

\begin{tabular}{cc}
\hline Sample ID & Quantification $(\% w / w)$ \\
\hline OPEHE & n.q. \\
OPEHC & n.q. \\
OPEHB & 0.12 \\
OPEHR & 4.90 \\
\hline
\end{tabular}

n.q. = not quantifiable.

\subsection{Colored Compound Identification}

The colored compounds extracted and subsequently purified with the previous methods, were characterized through spectrophotometric analysis methods (UV-vis analysis) and through UHPLC/UV-ESI-HRMS analysis, which showed the presence of betanin. The UV-vis analysis has already been illustrated in previous work performed by Scarano et al. [34]. The quantification of this compound in the extracts tested is shown in Table 4. Only the samples of mother solutions, the butanol extracts and residues showed the presence of this compound

The analysis showed that obtaining the colored compounds is initially very important in the stock solutions of the samples. The purification, carried out by extraction with solvents of increasing polarity and in particular the butanol fraction, does not remove coloring molecules from the residual solution. Purification is very useful to recover bioactive compounds in individual fractions that can be used in nutraceutical or functional foods applications. The remaining part (residual solution), rich in technologically functional compounds, can be directed to technological applications for natural dyes.

\subsection{UHPLC/UV-ESI-HRMS Analysis}

OFP extract samples subjected to UHPLC/UV-ESI-HRMS analysis with negative and positive ion analysis are shown in Table 5, in Supplementary Tables S1 and S2, respectively. In Table 5, only identify peaks in the chromatogram are reported.

Table 5. Characterization of the identified compounds present in the analyzed OFP extracts (negative ion analysis).

\begin{tabular}{ccccc}
\hline Peak & Rt (Min) & Mass Negative [M-H] $]^{-}$ & MS/MS $\mathbf{m} / z$ & Assigned Identity \\
\hline 2 & 1.13 & 215.0318 & $179,85,59$ & Apegenin-7-O-glucoside \\
3 & 1.17 & 191.0187 & 111,87 & [2H-] \\
6 & 1.22 & 179.0552 & $89,71,59$ & Citric acid \\
7 & 5.36 & 255.0509 & $193,179,165$ & Glucose \\
9 & 8.75 & 355.1038 & $193,175,160$ & Piscidic acid \\
10 & 9.14 & 239.0559 & $221,179,149$ & Eucomic acid \\
11 & 9.66 & 355.1033 & $295,235,193$ & Ferulic acid-C-hexoside \\
16 & 14.22 & 223.0608 & $163,133,91$ & Sinapic acid \\
17 & 14.55 & 613.2143 & $209,195,165$ & Syrinigyl(t8-O-4)guaiacyl \\
21 & 15.03 & 741.1891 & $300,271,255$ & Rutin-pentoside \\
22 & 16.27 & 496.2460 & $346,149,134$ & Protocatecuic acid \\
23 & 16.45 & 579.1357 & $417,181,166$ & derivative \\
24 & 16.61 & 769.2206 & 314,286 & Naringin \\
25 & 16.77 & 755.2276 & 314,271 & [IG1] \\
26 & 17.02 & 609.1467 & $314,299,271$ & [IG2]/[IG3] \\
27 & 18.09 & 623.1620 & 315,299 & [IG4] \\
29 & 19.06 & 431.0974 & $193,165,134$ & Apegenin-7-O-glucoside \\
31 & 21.39 & 315.0507 & 300,151 & Isorhamnetin \\
35 & 22.21 & 329.1246 & $229,211,171$ & Cirsiliol \\
38 & 24.80 & 339.2329 & 163 & Vulgaxanthin II \\
\hline
\end{tabular}


Table 6 (complete results in Supplementary Tables S3 and S4) show the presence of the compounds for each extract analyzed.

Table 6. Presence of the identified compounds in the analyzed OFP extract samples (negative ion analysis).

\begin{tabular}{|c|c|c|c|c|c|c|c|c|c|c|c|c|c|c|c|}
\hline Peak & $\begin{array}{l}\Sigma \\
0 \\
0 \\
0 \\
0 \\
0\end{array}$ & $\begin{array}{l}\text { rud } \\
0 \\
0 \\
0 \\
0\end{array}$ & 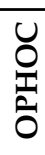 & 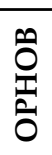 & 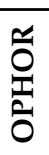 & 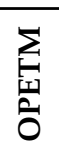 & 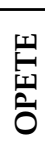 & 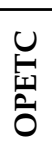 & 党 & $\begin{array}{l}\mathfrak{H} \\
\vdots \\
0\end{array}$ & $\begin{array}{l}\sum_{1} \\
\text { ti } \\
\text { ô }\end{array}$ & 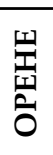 & 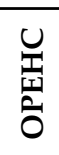 & 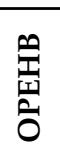 & 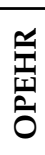 \\
\hline 2 & - & - & - & - & - & $X$ & $x$ & - & $X$ & $x$ & $x$ & $X$ & $x$ & $x$ & $x$ \\
\hline 3 & - & - & - & - & - & - & - & - & - & - & $x$ & - & - & - & $x$ \\
\hline 6 & - & - & $x$ & $x$ & $x$ & $x$ & $x$ & - & $x$ & $x$ & $x$ & $x$ & $x$ & $x$ & $x$ \\
\hline 7 & $x$ & - & - & $x$ & $x$ & $x$ & - & - & $x$ & $x$ & $x$ & $x$ & $x$ & $x$ & $x$ \\
\hline 9 & - & - & - & $x$ & - & $x$ & - & - & - & - & $x$ & - & - & $x$ & - \\
\hline 10 & $x$ & - & - & $x$ & $x$ & $x$ & & $x$ & $x$ & $x$ & $x$ & $X$ & $x$ & $x$ & $x$ \\
\hline 11 & - & - & - & $x$ & - & $x$ & - & - & - & - & $x$ & - & - & $x$ & - \\
\hline 16 & $x$ & - & - & $x$ & - & $X$ & - & $X$ & $X$ & - & $x$ & - & - & $x$ & $x$ \\
\hline 17 & - & - & - & $x$ & - & - & - & - & $x$ & - & - & - & - & $X$ & - \\
\hline 21 & - & - & - & $x$ & - & - & - & - & - & - & - & - & - & $X$ & - \\
\hline 22 & - & - & - & $x$ & - & $x$ & - & $x$ & $x$ & - & $x$ & - & $x$ & $x$ & - \\
\hline 23 & $x$ & - & $x$ & $x$ & - & $X$ & - & $X$ & $X$ & - & $x$ & - & $x$ & $x$ & - \\
\hline 24 & $x$ & - & - & $x$ & - & $x$ & - & - & $X$ & - & $x$ & - & - & $x$ & - \\
\hline 25 & $x$ & - & - & $x$ & - & $x$ & - & - & $x$ & - & $x$ & - & - & $x$ & - \\
\hline 26 & - & - & - & $x$ & - & $x$ & - & - & $x$ & - & $x$ & - & - & $x$ & - \\
\hline 27 & - & - & - & - & - & $X$ & - & - & $X$ & - & $x$ & - & - & $x$ & - \\
\hline 29 & - & - & - & $x$ & - & - & - & - & $X$ & - & - & - & - & - & - \\
\hline 31 & $x$ & - & $x$ & - & - & $x$ & - & $x$ & $X$ & - & $x$ & - & $x$ & - & - \\
\hline 35 & - & - & $x$ & $x$ & - & $x$ & - & $x$ & - & - & $x$ & - & $x$ & $x$ & - \\
\hline 38 & $x$ & - & - & $X$ & - & - & - & - & $x$ & - & - & - & - & $X$ & - \\
\hline
\end{tabular}

The quantification (reported in Table 7) was carried out, for all samples, in negative polarity by using an internal standard solution corresponding to gallic acid with a concentration equal to $50 \mathrm{ppm}$ in methanol with a retention time of $3.20 \mathrm{~min}$ and an $\mathrm{m} / \mathrm{z}$ equal to $169.0134[\mathrm{MH}]^{-}$. The percentages shown in the table of the different analytes are expressed as a weight/weight percentage $(\% w / w)$ with respect to the weight of the dry extract.

Table 7. Quantification of the identified compounds in the analyzed OFP extract samples (expressed as a weight/weight percentage $(\% w / w)$ respect to the weight of the dry extract reported in Table 4$)$.

\begin{tabular}{|c|c|c|c|c|c|c|c|c|c|c|c|c|c|c|c|}
\hline Peak & 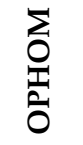 & 崩 & 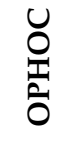 & $\begin{array}{l}0 \\
0 \\
0 \\
0 \\
0\end{array}$ & 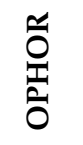 & $\sum_{\substack{\mid=1 \\
0}}^{\sum_{0}}$ & 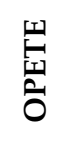 & $\begin{array}{l}u \\
\qquad \\
0 \\
0 \\
0\end{array}$ & $\begin{array}{l}n \\
\stackrel{n}{|c|} \\
\overline{0}\end{array}$ & 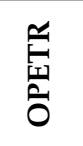 & $\sum_{\substack{\mid=1 \\
\overline{0}}}$ & 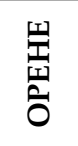 & 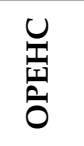 & 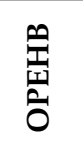 & 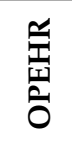 \\
\hline 2 & - & - & - & - & - & n.q. & n.q. & - & 4.38 & 5.75 & n.q. & 1.34 & 0.98 & 2.66 & 0.98 \\
\hline 3 & - & - & - & - & - & - & - & - & - & - & 7.23 & - & - & - & 0.98 \\
\hline 6 & - & - & 1.55 & 2.59 & 0.97 & 5.38 & n.q. & - & 4.38 & 5.75 & n.q. & 1.34 & 0.98 & 2.66 & 5.16 \\
\hline 7 & 1.60 & - & - & 3.29 & 0.22 & 1.72 & - & - & 2.22 & 1.89 & 3.14 & 0.52 & 0.24 & 0.86 & 3.35 \\
\hline 9 & - & - & - & n.q. & - & n.q. & - & - & - & - & n.q. & - & - & n.q. & - \\
\hline 10 & 2.30 & - & - & 7.87 & 0.43 & 3.44 & - & 0.56 & 11.00 & 2.16 & 2.58 & 0.39 & 0.10 & 3.08 & 2.03 \\
\hline 11 & - & - & - & 2.16 & - & n.q. & - & - & - & - & n.q. & - & - & n.q. & - \\
\hline 16 & 0.15 & - & - & 0.31 & - & 0.17 & - & 0.97 & 0.97 & - & 0.16 & - & - & 0.24 & n.q. \\
\hline 17 & - & - & - & 0.57 & - & - & - & - & 0.44 & - & - & - & - & n.q. & - \\
\hline 21 & - & - & - & 0.57 & - & - & - & - & - & - & - & - & - & n.q. & - \\
\hline 22 & - & - & - & n.q. & - & 0.12 & - & 1.76 & 0.48 & - & 0.12 & - & 0.31 & 0.16 & - \\
\hline
\end{tabular}


Table 7. Cont.

\begin{tabular}{|c|c|c|c|c|c|c|c|c|c|c|c|c|c|c|c|}
\hline Peak & $\begin{array}{l}\sum_{0} \\
\substack{1 \\
0 \\
\overline{0}}\end{array}$ & 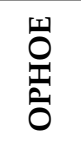 & 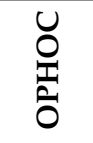 & 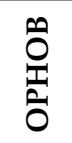 & 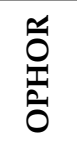 & $\sum_{\substack{|c| \\
0}}$ & 荘 & $\begin{array}{l}u \\
0 \\
0 \\
0 \\
0\end{array}$ & 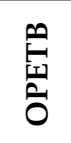 & 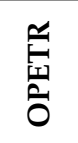 & 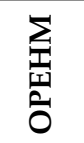 & 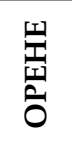 & 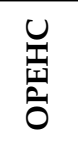 & 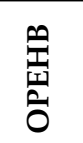 & 辤 \\
\hline 23 & 0.27 & - & 0.84 & 1.24 & - & 0.51 & - & 1.76 & n.q. & - & 0.49 & - & 1.24 & 0.82 & - \\
\hline 24 & 0.27 & - & - & 1.24 & - & 0.51 & - & - & 1.57 & - & 0.49 & - & - & 0.82 & - \\
\hline 25 & 0.27 & - & - & 1.24 & - & 0.51 & - & - & 1.57 & - & 0.49 & - & - & 0.82 & - \\
\hline 26 & - & - & - & 0.41 & - & 0.24 & - & - & 0.88 & - & 0.20 & - & - & 0.40 & - \\
\hline 27 & - & - & - & - & - & 0.30 & - & - & 1.28 & - & 0.26 & - & - & 0.61 & - \\
\hline 29 & - & - & - & n.q. & - & - & - & - & 0.47 & - & - & - & - & - & - \\
\hline 31 & n.q. & - & 2.19 & - & - & 0.24 & & 2.67 & 0.48 & - & 0.18 & - & 1.87 & - & - \\
\hline 35 & - & - & 12.77 & 1.01 & - & 0.36 & & 5.91 & - & - & 0.43 & - & 8.91 & 0.46 & - \\
\hline 38 & 0.39 & - & - & 1.18 & - & - & - & - & 0.33 & - & - & - & - & 0.23 & - \\
\hline 40 * & 0.50 & 0.50 & 0.50 & 0.50 & 0.50 & 0.50 & 0.50 & 0.50 & 0.50 & 0.50 & 0.50 & 0.50 & 0.50 & 0.50 & 0.50 \\
\hline
\end{tabular}

All chromatograms, mass data and fragmentations of individual compounds in individual samples can be found in the Supplementary Materials Section (Supplementary Figures S1-S16 and Supplementary Tables S1-S20).

\subsection{Assessing Dyeing Potency Using the CIELAB Method}

Color measurements of each stained tissue sample were taken at random positions on three replicates of each sample type. The values of the CIELAB color coordinates (Supplementary Figure S16: $L^{*}, a^{*}, b^{*}, C^{*} a b$ and $h_{a b}$ ) for the colored fibers treated in this study are given in Table 8.

Table 8. Colorimetric data. CIELAB color coordinate values (CIELAB units) of discs cotton, linen and wool fibers colored using the dye extract. Different superscripts letters indicate significant differences between treatments (U, DWM, DPL and DPA) at $p<0.05$ (Tukey pot-hoc).

\begin{tabular}{|c|c|c|c|c|}
\hline $\begin{array}{l}\text { CIELAB Color } \\
\text { Coordinates }\end{array}$ & $\mathbf{U}$ & DWM & DPL & DPA \\
\hline \multicolumn{5}{|c|}{ Wool fiber } \\
\hline $\mathrm{L}^{*}$ & $84.88 \pm 2.20^{a}$ & $23.75 \pm 2.44^{b}$ & $33.00 \pm 4.30^{\mathrm{c}}$ & $27.75 \pm 2.38^{c}$ \\
\hline$a^{*}$ & $1.25 \pm 0.43^{\mathrm{a}}$ & $18.00 \pm 1.22^{b}$ & $28.00 \pm 2.18^{c}$ & $23.63 \pm 1.41^{\mathrm{d}}$ \\
\hline $\mathbf{b}^{*}$ & $4.87 \pm 0.93^{a}$ & $10.75 \pm 0.97^{b}$ & $16.88 \pm 1.27^{\mathrm{c}}$ & $14.63 \pm 0.70^{c}$ \\
\hline $\mathrm{C}^{*}{ }_{\mathrm{ab}}$ & $5.07 \pm 0.84^{\mathrm{a}}$ & $20.97 \pm 1.46^{b}$ & $32.70 \pm 2.46^{\mathrm{c}}$ & $27.79 \pm 1.42^{\mathrm{c}}$ \\
\hline $\mathbf{h}_{\mathrm{ab}}$ & $74.93^{\circ} \pm 6.80^{\circ} \mathrm{a}$ & $30.05^{\circ} \pm 1.17^{\circ \mathrm{b}}$ & $35.07^{\circ} \pm 1.09^{\circ} \mathrm{c}$ & $34.75^{\circ} \pm 1.71^{\circ} \mathrm{c}$ \\
\hline \multicolumn{5}{|c|}{ Linen fiber } \\
\hline $\mathrm{L}^{*}$ & $91.50 \pm 1.87^{a}$ & $32.50 \pm 3.64^{b}$ & $39.13 \pm 1.83^{c}$ & $37.38 \pm 4.36^{c}$ \\
\hline$a^{*}$ & $-0.25 \pm 0.08^{a}$ & $15.38 \pm 1.11^{\mathrm{b}}$ & $26.38 \pm 1.80^{\mathrm{c}}$ & $16.75 \pm 2.05^{b}$ \\
\hline $\mathbf{b}^{*}$ & $9.00 \pm 1.12^{\mathrm{a}}$ & $8.88 \pm 0.33^{b}$ & $15.25 \pm 0.83^{c}$ & $11.63 \pm 1.49^{\mathrm{d}}$ \\
\hline $\mathrm{C}_{\mathrm{ab}}^{*}$ & $9.03 \pm 1.11^{\mathrm{a}}$ & $17.76 \pm 1.10^{b}$ & $30.47 \pm 1.90^{\mathrm{c}}$ & $20.40 \pm 2.46^{\mathrm{d}}$ \\
\hline $\mathbf{h}_{\mathrm{ab}}$ & $70.66^{\circ} \pm 5.33^{\circ} \mathrm{a}$ & $55.29^{\circ} \pm 0.90^{\circ} \mathrm{b}$ & $34.83^{\circ} \pm 1.76^{\circ} \mathrm{c}$ & $39.64^{\circ} \pm 0.85^{\circ} \mathrm{c}$ \\
\hline \multicolumn{5}{|c|}{ Cotton fiber } \\
\hline$L^{*}$ & $87.75 \pm 1.74^{\mathrm{a}}$ & $40.13 \pm 1.76^{b}$ & $40.63 \pm 3.00^{b}$ & $39.38 \pm 2.74^{b}$ \\
\hline$a^{*}$ & $1.38 \pm 0.43^{\mathrm{a}}$ & $5.25 \pm 1.09^{b}$ & $18.63 \pm 2.83^{c}$ & $14.63 \pm 1.65^{\mathrm{d}}$ \\
\hline $\mathbf{b}^{*}$ & $2.62 \pm 0.19^{a}$ & $7.50 \pm 0.71^{b}$ & $12.88 \pm 1.45^{\mathrm{c}}$ & $12.13 \pm 1.54^{c}$ \\
\hline $\mathrm{C}^{*}{ }_{\mathrm{ab}}$ & $3.00 \pm 0.11^{\mathrm{a}}$ & $9.20 \pm 0.94^{b}$ & $22.65 \pm 3.11^{\mathrm{c}}$ & $19.09 \pm 2.16^{c}$ \\
\hline$h_{a b}$ & $61.53^{\circ} \pm 9.29^{\circ} \mathrm{a}$ & $30.82^{\circ} \pm 1.52^{\circ} \mathrm{b}$ & $31.09^{\circ} \pm 0.99^{\circ} \mathrm{b}$ & $31.80^{\circ} \pm 1.40^{\circ} \mathrm{b}$ \\
\hline
\end{tabular}

Data were expressed as the relative standard deviation, on measurements taken at random points on three replicates. $\mathrm{U}=$ Undyed. $\mathrm{DWM}=$ stained with extract dye without the use of mordants. DPL = pre-treatment with lemon juice. $\mathrm{DPA}=$ pre-treatment with aluminum potassium sulphate. 
The ANOVA analysis revealed significant difference (based on color parameters) between the treatments (Table 8). First, the U samples were significantly different from the colored samples indicating that the determination of colorimetric parameters did not provide bias. In addition, the parameters analyzed in the DWM sample are generally different than DPL and DPA. Thus, we observed specific differences (Table 9).

Table 9. Partial color differences $\left(\Delta \mathrm{L}^{*}, \Delta \mathrm{a}^{*}\right.$ and $\left.\Delta \mathrm{b}^{*}\right)$, 'chroma' differences $\left(\Delta \mathrm{C}_{\mathrm{ab}}^{*}\right)$, 'hue angle' differences $\left(\Delta \mathrm{h}_{\mathrm{ab}}\right)$ and total color difference $\left(\Delta \mathrm{E}_{\mathrm{ab}}^{*}\right)$ between the dyed fabrics.

\begin{tabular}{|c|c|c|c|c|c|}
\hline & DWM-U & DPL-U & DPA-U & DPL-DWM & DPA-DWM \\
\hline \multicolumn{6}{|c|}{ Wool fiber } \\
\hline$\Delta \mathrm{L}^{*}$ & 52.38 & 45.75 & 47.50 & 6.63 & 4.88 \\
\hline$\Delta \mathbf{a}^{*}$ & 14.13 & 25.13 & 15.50 & 11.00 & 1.38 \\
\hline$\Delta \mathrm{b}^{*}$ & 4.00 & 10.38 & 6.75 & 6.38 & 2.75 \\
\hline$\Delta \mathrm{C}_{\mathrm{ab}}^{*}$ & 54.39 & 53.22 & 50.42 & 14.34 & 5.76 \\
\hline$\Delta \mathrm{h}_{\mathrm{ab}}$ & 12.69 & 25.41 & 15.33 & 12.72 & 2.64 \\
\hline$\Delta \mathrm{E}_{\mathrm{ab}}^{*}$ & 44.87 & -44.86 & 40.18 & 0.01 & 4.70 \\
\hline \multicolumn{6}{|c|}{ Linen fiber } \\
\hline$\Delta \mathrm{L}^{*}$ & 51.375 & 50.88 & 52.13 & 0.50 & 0.75 \\
\hline$\Delta \mathbf{a}^{*}$ & 5.5 & 18.88 & 14.88 & 13.38 & 9.38 \\
\hline$\Delta \mathrm{b}^{*}$ & 1.5 & 3.88 & 3.13 & 5.38 & 4.63 \\
\hline$\Delta \mathrm{C}_{\mathrm{ab}}^{*}$ & 51.69 & 54.40 & 54.30 & 14.42 & 10.48 \\
\hline$\Delta \mathbf{h}_{\mathrm{ab}}$ & 0.14 & 13.60 & 9.95 & 13.45 & 9.81 \\
\hline$\Delta \mathbf{E}^{*}{ }_{\mathrm{ab}}$ & 15.37 & 35.83 & 31.02 & 20.46 & 15.65 \\
\hline \multicolumn{6}{|c|}{ Cotton fiber } \\
\hline$\Delta \mathrm{L}^{*}$ & 64.00 & 54.75 & 60.00 & 9.25 & 4.00 \\
\hline$\Delta \mathbf{a}^{*}$ & 16.63 & 26.63 & 22.25 & 10.00 & 5.63 \\
\hline$\Delta \mathbf{b}^{*}$ & 8.13 & 14.25 & 12.00 & 6.13 & 3.88 \\
\hline$\Delta \mathrm{C}_{\mathrm{ab}}^{*}$ & 66.62 & 62.53 & 65.11 & 14.94 & 7.92 \\
\hline$\Delta \mathrm{h}_{\mathrm{ab}}^{\mathrm{av}}$ & 17.97 & 29.70 & 24.79 & 11.72 & 6.82 \\
\hline$\Delta \mathrm{E}_{\mathrm{ab}}^{*}$ & 30.71 & 30.45 & -29.74 & 0.26 & 0.97 \\
\hline
\end{tabular}

$\mathrm{U}=$ Undyed. DWM = stained with extract dye without the use of mordants. DPL = pre-treatment with lemon juice. DPA = pre-treatment with aluminum potassium sulphate.

The staining data in Table 8 for all three fibers and all three co-locations, with and without an etchant, show that the staining was effective compared to the control fibers $U$. All data were appropriately discussed in Sections 4.8 and 4.9. The staining data were also addressed by discussing the differences between the co-located fibers (DWM, DPL, DPA) and the control fibers (U), as well as the difference between the two staining treatments for the stained fibers (DPL and DPA) with the stained fibers without an etchant (DWM).

An evaluation of the resistance of the dye to washing and exposure to light was carried out $[37,38]$. The wash and light fastness values with a brief description of the fastness assessment are given in Table 10. All coloring results can be seen in Figure 3.

Table 10. Wash and light fastness values for the colored fibers.

\begin{tabular}{ccccc}
\hline Samples & Wash Fastness & Description & Light Fastness & Description \\
\hline Wool & & & & \\
\hline DWM & $5-6$ & Visible loss of coloration & 7 & Acceptable loss of depth \\
DPL & 8 & Acceptable loss of coloration & 7 & Acceptable loss of depth \\
DPA & 7 & Low loss of coloration & 8 & Slight loss of depth \\
\hline Linen & &
\end{tabular}


Table 10. Cont.

\begin{tabular}{ccccc}
\hline Samples & Wash Fastness & Description & Light Fastness & Description \\
\hline DWM & 6 & Visible loss of coloration & 6 & Low loss of depth \\
DPL & 6 & Visible loss of coloration & 6 & Low loss of depth \\
DPA & $7-8$ & Acceptable loss of coloration & 7 & Acceptable loss of depth \\
\hline Cotton & & & & \\
\hline DWM & 7 & Low loss of coloration & 7 & Acceptable loss of depth \\
DPL & $7-8$ & Acceptable loss of coloration & 8 & Slight loss of depth \\
DPA & $8-9$ & Slight loss of coloration & 9 & No loss of depth \\
\hline
\end{tabular}

$\mathrm{U}=$ Undyed. DWM = stained with extract dye without the use of mordants. DPL = pre-treatment with lemon juice. DPA = pre-treatment with aluminum potassium sulphate.
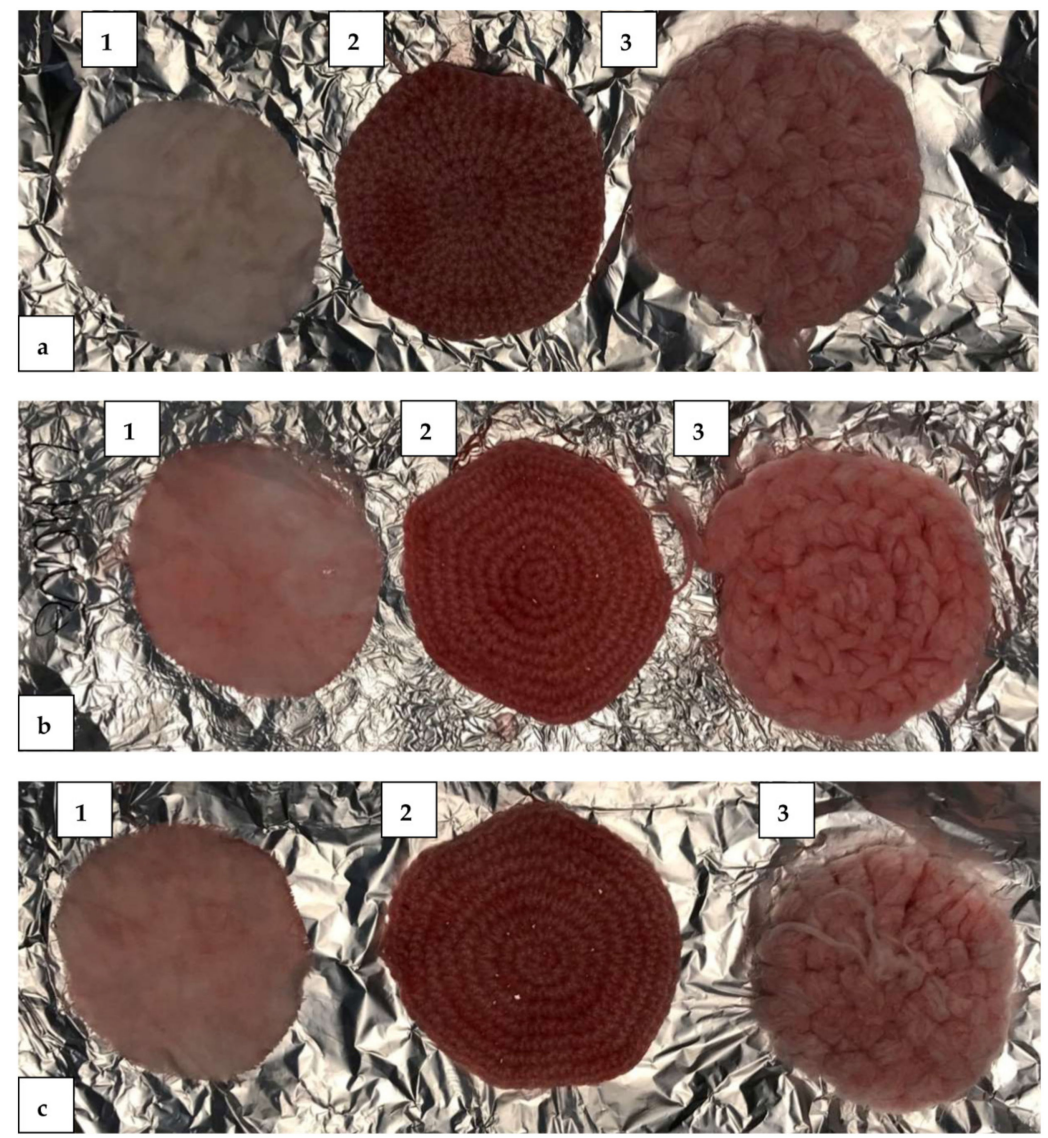

Figure 3. Fiber discs of (1) linen. (2) cotton and (3) wool after treatment with dye solutions: (a) colored with dye extract without the use of mordants (DWM); (b) stained with dye extract with pre-treatment with lemon juice (DPL); (c) stained with dye extract with pre-treatment with aluminum potassium sulphate (DPA).

\section{Discussion}

\subsection{Parameters of the Extracts}

An important result (in degrees Brix) reported in Table 1 was obtained in the evaluation of the soluble solid that within the extracts, the specific gravity was very low in relation to the other components present $[39,40]$. This finding would suggest that in the total phenolic compound content analysis, the value is almost totally due to the presence of phenols: in fact, there are several substances that can interfere with the Folin-Ciocâlteu reagent (i.e., high concentrations of reducing sugars, ammonium sulphate, sulfhydryl compounds, etc.) [41-44]. 


\subsection{Polyphenolic Content}

The total phenolic compound yield in the $\mathrm{EtOH}: \mathrm{H}_{2} \mathrm{O}(8: 2)$ was higher than in the other solvents for both extraction methods. This result, in agreement with the literature [29], showed that the EtOH: $\mathrm{H}_{2} \mathrm{O}(8: 2)$ is the most suitable solvent for the extraction of phenolic compounds, and the TPC is improved by increasing the polarity of the solvent, regardless of the extraction method. However, concerning the extraction method, the present results are showed that TPC in OFP extracted with NE in EtOH: $\mathrm{H}_{2} \mathrm{O}(8: 2)$ was significantly higher than in those extracted with ME. Although there was TPC in the $\mathrm{H}_{2} \mathrm{O}$ extract (Table 2), its phenol content is poor compared to the EtOH extract, which also has a high extraction yield. This phenomenon could be explained by the ability of water to dissolve residual substances, such as organic acids and sugars, which could interfere with the quantification of phenols [45]. Furthermore, extractions carried out for prolonged periods may be the cause of this extraction of TPC in $\mathrm{H}_{2} \mathrm{O}$. NE still extracts a component of TPC by mechanical action. This finding shows that the phenolic compound content of the OFP extracts is not only influenced by the polarity of the solvent but also by the extraction process and method. It is interesting to see how the extraction times, for the sample/solvent ratios used in this work, do not particularly influence the amount of extracted TPC, which in any case grows in proportion to the higher extraction times.

Taking care to maintain the same extraction conditions for the methods used in the comparison, it is possible to ascertain that NE is a technique that allows us to obtain better performing extracts, as it performs an active extraction and not a passive one as in the case of ME [31,46].

\subsection{Radical Scavenging Activity}

The radical scavenging activity of the extracts on DPPH, expressed as \% free radical Inhibition (I\%). The acquired data are shown graphically in Figure 2 and show good anti-radical activity of the extracts produced with both techniques, with a slight preference towards extraction by maceration compared to extraction by Extractor Naviglio ${ }^{\circledR}[47,48]$.

These data, as previously reported, show a slight preference towards the extraction of molecules with anti-radical action by maceration compared to the extraction by Extractor Naviglio ${ }^{\circledR}$. Most likely, this result is due to the extended extraction times $(24 \mathrm{~h})$ that will be reported in the future, for this specific assay with minor extraction times for both techniques. As the literature suggests, the antioxidant activity of the extracts depends not only on its total phenolic compound content but also on the presence of chemical classes other than phenolic compounds that can react with radicals $[49,50]$. In addition, the extracts obtained with the different solvents and methods include minor components that could have a major/minor effect on the antioxidant capacity depending on each extract [51]. The interaction between phenolic compounds in the crude extracts may have a synergistic or antagonistic effect resulting in large variation in the antioxidant activities [52].

\subsection{Extraction Time Evaluation}

The effect of the extraction time was studied with bidistilled water, $\mathrm{EtOH}$ and a solution of $\mathrm{EtOH}$ and $\mathrm{H}_{2} \mathrm{O}$ in 8:2 ratio as the extraction solvent. The values did not increase significantly when the extraction time was increased from 8 to $24 \mathrm{~h}$, but it increased significantly when the extraction time was increased from 2 to $8 \mathrm{~h}$, as shown in Figure 1 . After $2 \mathrm{~h}$, the extraction was close to $80 \%$ of the final content in the TPC. Extraction times between 8 and $24 \mathrm{~h}$ led to the highest recoveries with no significant differences among them.

\subsection{Extraction Method Evaluation}

The results of the extraction of polyphenolic compounds by the maceration method were substantially in agreement with the values found in several works in the literature $[53,54]$. Extraction of polyphenolic compounds by the NE method showed a strong increase in value for OFP extract when comparing the TPC values. Thus, NE is the best method for the same extraction duration and extraction solvent. The use of the NE method, 
compared to the ME method, proved to be a good alternative protocol, with very good yields in the extraction of phenolic bioactive compounds in general. Regarding the extraction of molecules with antiradical activity, the data acquired for long extraction times showed no substantial differences between ME and NE extraction with the same extraction duration and extraction solvent. The use of Extractor Naviglio ${ }^{\circledR}$ as an extraction technique has shown nutraceutical value in the extraction of polyphenols and other compounds from a matrix, such as the OFP. The advantage of this technique is the possibility to operate in the total absence of organic solvents or at least to operate with food grade solvents, protecting both the extract and the residual matrix from contamination. Along with obtaining bioactive compounds, obtaining coloring compounds is of great interest, as natural dyes can be an excellent alternative to synthetic dyes that cause great damage to the environment. The NE method was again found to be the best performing method in terms of yields of color molecules for the same extraction time and extraction solvent.

\subsection{Coloured Compound Extractions Evaluation}

The extraction of color compounds from prickly pear peel, such as betanins, is an excellent alternative to synthetic dyes. In this work, extraction using conventional techniques such as ME and innovative techniques such as NE, compared, could endorse the possibility of obtaining betanins for use as dyes. It has been shown that, in fact, natural dyes can be used in technological applications as in the work developed by Scarano et al. [34]. The use of innovative techniques such as NE has made it possible to obtain betanins more efficiently and quickly than conventional techniques such as ME, while also using food-grade solvents that allow them to be used in food. From Table 4, it can be seen that the extracts obtained with NE have a very high betanin content and that these molecules are easily purified, with minimal losses in the various purification steps, guaranteeing an important result. Therefore, overall, the extraction of color molecules such as betanins can be conducted in a cost-effective manner, using innovative and scalable technologies based on the concept of economic and environmental sustainability.

\subsection{Bioactive Compounds Extraction Evaluation}

Another important result concerns obtaining bioactive compounds from a waste matrix, such as prickly pear peel, by means of innovative methods and simple separation techniques that make it possible to obtain samples with a good degree of purity and weight. The bioactive compounds obtained can be used in nutraceuticals and functional foods, thanks to extractions carried out both with food-grade solvents and with methods that, even if they use solvents harmful to humans, can be purified in an economic and sustainable manner as they can be reused. The extracted and purified products are free of these harmful solvents. Purifications of samples using butanol in particular have a high content of bioactive compounds. The extraction using these techniques and methods is therefore a good alternative to conventional methods and makes it possible to reduce economic costs and food waste from a sustainable perspective, thereby enhancing the value of compounds that would certainly be lost or disposed of improperly.

\subsection{Dyeing Process Evaluation by CIELAB Method}

The parameter $L^{*}$ (color brightness) varied between 23.75 and 30.00 CIELAB units for the colored wool fiber samples, between 32.50 and 39.13 CIELAB units for the colored linen fiber samples and between 39.38 and 40.63 for the coloured cotton fiber samples, having $84.88,91.50$ and 87.75 CIELAB units as the control L* value for wool, linen and cotton fibers (identified as uncolored fabric, $U$ ), respectively, indicating a clearly perceptible change in fiber color due to dyeing, or $\Delta \mathrm{L}^{*}>45$ CIELAB units, a significant color difference.

The value of $\mathrm{a}^{*}$ (associated with the change from green $(-)$ to red $(+)$ ) varied over a data range of $1.25(\mathrm{U})$ to $18.00(\mathrm{DWM}), 28.00$ (DPL), 23.63 (DPA), for wool fiber, over a data range of $-0.25(\mathrm{U})$ to $15.38(\mathrm{DWM}), 26.38(\mathrm{DPL}), 16.75$ (DPA), for the linen fiber and $1.38(\mathrm{U})$ 
to 5.25 (DWM), 18.63 (DPL), 14.63 (DPA), for the cotton fiber: this numerical identification means that the fabric was given a reddish color.

The change in $b^{*}$ (associated with the change in the range from blueness $(-)$ to yellowness (+)) occurs in a data range from 4.87 (U) to 10.75 (DWM), 16.88 (DPL), 14.63 (DPA), for wool fiber, in a data range of 9.00 (U) to 8.88 (DWM), 15.25 (DPL), 11.63 (DPA), for linen fiber and 2.62 (U) to 7.50 (DWM), 12.88 (DPL), 12.13 (DPA), for cotton fiber.

The parameter $\mathrm{C}^{*}$ ab (color saturation) varied in a data range of $5.07(\mathrm{U})$ to 20.97 (DWM), 32.70 (DPL), 27.79 (DPA), for wool fiber, in a data range of 9.03 (U) to 17.76 (DWM), 30.47 (DPL), 20.40 (DPA), for linen fiber and 3.00 (U) to 9.20 (DWM), 22.65 (DPL), 19.09 (DPA), for the cotton fiber; in all three cases there was an increase in the value between 6 and 28 CIELAB units, which means a more pronounced color saturation and thus effective coloration.

The dye angle, $\mathrm{h}_{\mathrm{ab}}$, for the dyed fibers with and without mordant, was in the range $30.05^{\circ}$ and $55.29^{\circ}$ (DWM), i.e., they were in the red-pink dye zone.

From these measurements it can be observed that the color components isolated from $O$. ficus-indica lead to a color specific to the type of fruit used and both mordants used influence the depth of the shades, as is reported in the literature $[7,55,56]$. The fact that the mordants allow the dye applied to wool, linen and cotton fibers to be fixed is certainly due to the formation of a chemical bridge between the dye and the fibers [13,57].

The $h_{a b}$ value represents the main attribute of color perception, therefore, the results obtained show us that the use of mordant, whether lemon juice or rock alum, did not have significant altering effects on color values.

From Table 9 it is possible to see what differences there are in the absorption of the dye depending on the type of dyeing carried out (with or without mordant): between wool, linen and cotton, it is greater for cotton, which seems to be a good textile support for the dye obtained from $O$. ficus-indica, as has already been proven previously, but under different conditions.

\subsection{Dyed Fibers Evaluation}

The dye applied to the fibers without the use of mordants produced washing fastness properties equivalent to, but not superior to, fabrics where a mordant was applied. Its fastness to light was lower than that of most samples. The use of mordants therefore implies better anchorage on a manufactured fabric than on a fabric to which no mordant is applied.

\section{Conclusions}

In conclusion, the phenols and molecules with an anti-radical mechanism extracted from OFPs were influenced by the type of solvent used in the extraction and the duration and method of extraction. The optimal extraction conditions with NE seem to be the same as those found in the literature, but with better time and performance. This is demonstrated by comparing them with conventional methods such as maceration. In fact, under the same conditions of the same solvent and the ratio of solid to solvent in the extraction phase, it is possible to see that there is a significant increase in the number of molecules obtained from TPCs compared with the dry residue obtained. The NE is a technique that allows us, under the same extraction conditions, to obtain better performing extracts, as it performs an active extraction and not a passive one as in the case of the ME.

It can be observed that when comparing the methods, with the same solvent, both for $\mathrm{H}_{2} \mathrm{O}$ and $\mathrm{EtOH}: \mathrm{H}_{2} \mathrm{O}(8: 2)$ the NE is better than the ME. Whereas for extracts in EtOH there is no substantial difference between the two methods.

The result of the content of molecules with a low anti-radical mechanism, on the other hand, is most probably due to prolonged extraction times. In fact, prolonged interaction with the solvent (in some cases), light and air itself is counterproductive in the preservation of molecules with antiradical action. For example, the use of a controlled atmosphere (nitrogen) can preserve them. We are currently investigating technological solutions for 
NE that help, also with the help of nitrogen, to avoid the degradation of molecules with antiradical action.

Overall, however, with respect to the results obtained, the use of NE to produce extracts rich in phenols and molecules with an anti-radical mechanism has proved to be a good approach to the new formulation of extracts rich in molecules of proven nutraceutical and functional food use. It also benefits the SRMs obtained downstream of the extraction process, which are now depleted of bioactive compounds and, after a short air-drying process, remain stable indefinitely without degradation or mold formation (this is the subject of another study).

At the same time. the extraction. purification and utilization of these molecules and coloring molecules, obtained from a waste material such as OFPs, is certainly a viable option from a sustainability perspective.

Coloring compounds, such as betanin contained in OFPs, are very important natural compounds that could be considered for technological applications in the field of food coloring and fabric dyeing. The possibility of obtaining these molecules using innovative techniques and methodologies such as NE can bring great advantages in the field of application. In this work, the extraction of betanins from the skin of the prickly pear, which is still a waste product, can bring great advantages from an economic, social and, above all, sustainability perspective.

Supplementary Materials: The following are available online at https://www.mdpi.com/article/ 10.3390/agronomy12020388/s1, Figure S1: OPHOM sample chromatogram, Figure S2: OPHOH sample chromatogram, Figure S3: OPHOC sample chromatogram, Figure S4: OPHOB sample chromatogram, Figure S5: OPHOR sample chromatogram, Figure S6: OPETM sample chromatogram, Figure S7: OPETE sample chromatogram, Figure S8: OPETC sample chromatogram, Figure S9: OPETB sample chromatogram, Figure S10: OPETR sample chromatogram, Figure S11: OPEHM sample chromatogram, Figure S12: OPEHE sample chromatogram, Figure S13: OPEHC sample chromatogram, Figure S14: OPEHB sample chromatogram, Figure S15: OPEHR sample chromatogram, Figure S16: CIELAB color chart [43], Table S1: Characterization of all compounds present in the analyzed OFP extracts (negative ion analysis), Table S2: Characterization of the compounds present in the analyzed OFP extracts (positive ion analysis)*, Table S3: Presence of the identified compounds in the analysed OFP extract samples (negative ion analysis), Table S4: Presence of the identified compounds in the analysed OFP extract samples (positive ion analysis), Table S5: Quantification of all compounds found in the analysed OFP extract samples (expressed as weight/weight percentage ( $\% w / w)$ of dry extract weight in Table 4), Table S6: Characterization of the compounds present in the OPHOM sample chromatogram, Table S7: Characterization of the compounds present in the OPHOE sample chromatogram, Table S8: Characterization of the compounds present in the OPHOC sample chromatogram, Table S9: Characterization of the compounds present in the OPHOB sample chromatogram, Table S10: Characterization of the compounds present in the OPHOR sample chromatogram, Table S11: Characterization of the compounds present in the OPETM sample chromatogram, Table S12: Characterization of the compounds present in the OPETE sample chromatogram, Table S13: Characterization of the compounds present in the OPETC sample chromatogram, Table S14: Characterization of the compounds present in the OPETB sample chromatogram, Table S15: Characterization of the compounds present in the OPETR sample chromatogram, Table S16: Characterization of the compounds present in the OPEHM sample chromatogram, Table S17: Characterization of the compounds present in the OPEHE sample chromatogram, Table S18: Characterization of the compounds present in the OPEHC sample chromatogram, Table S19: Characterization of the compounds present in the OPEHB sample chromatogram, Table S20: Characterization of the compounds present in the OPEHR sample chromatogram.

Author Contributions: Conceptualization, P.S., C.G. and R.S.; methodology, P.S. and C.G.; validation, R.S., C.G., D.Z., M.T. and P.S.; formal analysis, M.T. and P.S.; investigation, M.T. and P.S.; data curation, P.S., D.Z., A.P., C.G. and R.S.; writing-original draft preparation, P.S., M.T., D.Z., A.P., C.G. and R.S.; writing-review and editing, C.G., R.S., D.Z. and M.T.; supervision, C.G. and R.S.; project administration, P.S., C.G. and R.S. All authors have read and agreed to the published version of the manuscript. 
Funding: This research received no external funding.

Institutional Review Board Statement: Not applicable.

Informed Consent Statement: Not applicable.

Data Availability Statement: The data presented in this study are available in the text of this article and in Supplementary Materials.

Acknowledgments: Thanks to the UMG Agro Analisi laboratory. facility of the Magna Græcia University of Catanzaro. which supported us in the analysis performed on the samples.

Conflicts of Interest: The authors have no conflict of interest to declare.

\section{References}

1. Boonsong, P.; Laohakunjit, N.; Kerdchoechuen, O. Natural pigments from six species of Thai plants extracted by water for hair dyeing product application. J. Clean. Prod. 2012, 37, 93-106. [CrossRef]

2. $\quad$ Sánchez, F.D.; López, E.M.S.; Kerstupp, S.F.; Ibarra, R.V.; Scheinvar, L. Colorant Extraction from red prickly pear (Opuntia lasiacantha) for food application. J. Environ. 2006, 5, 1330-1337.

3. Ardila-Leal, L.D.; Poutou-Piñales, R.A.; Pedroza-Rodríguez, A.M.; Quevedo-Hidalgo, B.E. A brief history of colour, the environmental impact of synthetic dyes and removal by using laccases. Molecules 2021, 26, 3813. [CrossRef] [PubMed]

4. Ganesan, A. The impact of natural products upon modern drug discovery. Curr. Opin. Chem. Biol. 2008, 12, 306-317. [CrossRef]

5. Pleissner, D. Recycling and reuse of food waste. Curr. Opin. Green Sustain. Chem. 2018, 13, 39-43. [CrossRef]

6. Schreck, M.; Wagner, J. Incentivizing secondary raw material markets for sustainable waste management. Waste Manag. 2017, 67, 354-359. [CrossRef]

7. Sanjeeda, I.; Ansari, T.N. Natural Dyes: Their Sources and Ecofriendly. J. Environ. Res. Dev. 2014, 8, $683-688$.

8. Carocho, M.; Morales, P.; Ferreira, I.C.F.R. Antioxidants: Reviewing the chemistry, food applications, legislation and role as preservatives. Trends Food Sci. Technol. 2018, 71, 107-120. [CrossRef]

9. Llorach, R.; Espín, J.C.; Tomás-Barberán, F.A.; Ferreres, F. Valorization of cauliflower (Brassica oleracea L. var. botrytis) by-products as a source of antioxidant phenolics. J. Agric. Food Chem. 2003, 51, 2181-2187. [CrossRef]

10. Ayala-Zavala, J.F.; Vega-Vega, V.; Rosas-Domínguez, C.; Palafox-Carlos, H.; Villa-Rodriguez, J.A.; Siddiqui, M.W.; Dávila-Aviña, J.E.; González-Aguilar, G.A. Agro-industrial potential of exotic fruit byproducts as a source of food additives. Food Res. Int. 2011, 44, 1866-1874. [CrossRef]

11. Tiwari, O.P.; Tripathi, Y.B. Antioxidant properties of different fractions of Vitex negundo Linn. Food Chem. 2007, 100, 1170-1176. [CrossRef]

12. Wang, K.J.; Zhang, Y.J.; Yang, C.R. Antioxidant phenolic compounds from rhizomes of Polygonum paleaceum. J. Ethnopharmacol. 2005, 96, 483-487. [CrossRef]

13. Meksi, N.; Haddar, W.; Hammami, S.; Mhenni, M.F. Olive mill wastewater: A potential source of natural dyes for textile dyeing Ind. Crops Prod. 2012, 40, 103-109. [CrossRef]

14. Shi, J.; Le Maguer, M. Lycopene in tomatoes: Chemical and physical properties affected by food processing. Crit. Rev. Food Sci. Nutr. 2000, 40, 1-42. [CrossRef]

15. Aragona, M.; Lauriano, E.R.; Pergolizzi, S.; Faggio, C. Opuntia ficus-indica (L.) Miller as a source of bioactivity compounds for health and nutrition. Nat. Prod. Res. 2018, 32, 2037-2049. [CrossRef]

16. El-razek, F.H.; Hassan, A.A. Nutritional value and hypoglycemic effect of prickly cactus pear (Opuntia ficus-indica) fruit juice in alloxan-induced diabetic rats. Aust. J. Basic Appl. Sci. 2011, 5, 356-377.

17. Yeddes, N.; Chérif, J.K.; Ayadi, M.T. Comparative study of antioxidant power, polyphenols, flavonoids and betacyanins of peel and pulp of three Tunisian Opuntia forms. Pak. J. Biol. Sci. 2014, 17, 650-658. [CrossRef] [PubMed]

18. Royal Botanic Gardens Plants of the World Online I Kew Science. Available online: https: / / powo.science.kew.org/ (accessed on 21 January 2022).

19. Pignatti, S.; Guarino, R.; La Rosa, M. Flora d'Italia; Edagricole: Bologna, Italy, 2017; Volume 1, ISBN 9788850652426.

20. Butera, D.; Tesoriere, L.; Di Gaudio, F.; Bongiorno, A.; Allegra, M.; Pintaudi, A.M.; Kohen, R.; Livrea, M.A. Antioxidant activities of sicilian prickly pear (Opuntia ficus indica) fruit extracts and reducing properties of its betalains: Betanin and indicaxanthin. $J$. Agric. Food Chem. 2002, 50, 6895-6901. [CrossRef] [PubMed]

21. The United States Department of Agriculture (USDA). The PLANTS Database - National Plant Data Center; U.S. Department of Agriculture: Baton Rouge, LA, USA, 2009.

22. Kiesling, R. Origen, Domesticación y Distribución de Opuntia ficus-indica. J. Prof. Assoc. Cactus Dev. 1995, 3, 50-59.

23. Inglese, P.; Mondragon, C.; Nefzaoui, A.; Sáenz, C. Crop Ecology, Cultivation and Uses of Cactus Pear; Food and Agriculture Organization of the United Nations: Rome, Italy; International Center for Agricultural Research in the Dry Areas: Coquimbo, Chile, 2017; ISBN 9251098603.

24. Gustavsson, J.; Cederberg, C.; Sonesson, U. Global Food Losses and Food Waste. In Proceedings of the Save Food Congress, Düsseldorf, Germany, 16 May 2011. 
25. El-Hawary, S.S.; Sobeh, M.; Badr, W.K.; Abdelfattah, M.A.O.; Ali, Z.Y.; El-Tantawy, M.E.; Rabeh, M.A.; Wink, M. HPLC-PDAMS/MS profiling of secondary metabolites from Opuntia ficus-indica cladode, peel and fruit pulp extracts and their antioxidant, neuroprotective effect in rats with aluminum chloride induced neurotoxicity. Saudi J. Biol. Sci. 2020, 27, 2829-2838. [CrossRef] [PubMed]

26. Smida, A.; Ncibi, S.; Taleb, J.; Saad, A.B.; Ncib, S.; Zourgui, L. Immunoprotective activity and antioxidant properties of cactus (Opuntia ficus indica) extract against chlorpyrifos toxicity in rats. Biomed. Pharmacother. 2017, 88, 844-851. [CrossRef]

27. Prieto, B.; Ferrer, P.; Sanmartín, P.; Cárdenes, V.; Silva, B. Color characterization of roofing slates from the Iberian Peninsula for restoration purposes. J. Cult. Herit. 2011, 12, 420-430. [CrossRef]

28. García-Cayuela, T.; Gómez-Maqueo, A.; Guajardo-Flores, D.; Welti-Chanes, J.; Cano, M.P. Characterization and quantification of individual betalain and phenolic compounds in Mexican and Spanish prickly pear (Opuntia ficus-indica L. Mill) tissues: A comparative study. J. Food Compos. Anal. 2019, 76, 1-13. [CrossRef]

29. Mohammedi, Z.; Atik, F. Impact of solvent extraction type on total polyphenols content and biological activity from Tamarix aphylla (L.) Karst. Int. J. Pharma Bio Sci. 2011, 2, 609-615.

30. Naviglio, D. Naviglio's principle and presentation of an innovative solid-liquid extraction technology: Extractor Naviglio ${ }^{\circledR}$. Anal. Lett. 2003, 36, 1647-1659. [CrossRef]

31. Naviglio, D.; Scarano, P.; Ciaravolo, M.; Gallo, M. Rapid solid-liquid dynamic extraction (RSLDE): A powerful and greener alternative to the latest solid-liquid extraction techniques. Foods 2019, 8, 245. [CrossRef] [PubMed]

32. Dewanto, V.; Xianzhong, W.; Adom, K.K.; Liu, R.H. Thermal processing enhances the nutritional value of tomatoes by increasing total antioxidant activity. J. Agric. Food Chem. 2002, 50, 3010-3014. [CrossRef]

33. Mosquera, O.M.; Correa, Y.M.; Buitrago, D.C.; Niño, J. Antioxidant activity of twenty five plants from Colombian biodiversity. Mem. Inst. Oswaldo Cruz 2007, 102, 631-634. [CrossRef]

34. Scarano, P.; Naviglio, D.; Prigioniero, A.; Tartaglia, M.; Postiglione, A.; Sciarrillo, R.; Guarino, C. Sustainability: Obtaining natural dyes from waste matrices using the prickly pear peels of Opuntia ficus-indica (L.) Miller. Agronomy 2020, 10, 528. [CrossRef]

35. Chan-Bacab, M.J.; Sanmartín, P.; Camacho-Chab, J.C.; Palomo-Ascanio, K.B.; Huitz-Quimé, H.E.; Ortega-Morales, B.O. Characterization and dyeing potential of colorant-bearing plants of the Mayan area in Yucatan Peninsula, Mexico. J. Clean. Prod. 2015, 91, 191-200. [CrossRef]

36. Alessi, P.J.; Carter, E.C.; Fairchild, M.D.; Hunt, R.W.; McCamy, C.S.; Kranicz, B.; Moore, J.R.; Morren, L.; Nobbs, J.H.; Ohno, Y.; et al. CIE—International Commission on Illumination Technical Report_Colorimetry; CIE 015-2004; Carter, E.C., Ohno, Y., Pointer, R.M., Robertson, A.R., Sève, R., Schanda, J.D., Witt, K., Eds.; International Commission on Illumination: Vienna, Austria, 2004.

37. Janani, L.; Winifred, D. Suitability of Dyes from Mulberry and Coffee Leaves on Silk Fabrics using Eco-Friendly Mordants. Int. J. Sci. Res. Publ. 2013, 3, 1-4.

38. Singh, S.V.; Purohit, M.C. Evaluation of colour fastness properties of natural dye extracted from Symplocos racemosa (Lodh) on wool fibres using combination of natural and synthetic mordants. Indian J. Fibre Text. Res. 2014, 39, 97-101.

39. Lamia, I.; Zouhir, C.; Youcef, A. Characterization and transformation of the Opuntia ficus indica fruits. J. Food Meas. Charact. 2018, 12, 2349-2357. [CrossRef]

40. Sáenz, C.; Estévez, A.M.; Sepúlveda, E.; Mecklenburg, P. Cactus pear fruit: A new source for a natural sweetener. Plant Foods Hum. Nutr. 1998, 52, 141-149. [CrossRef]

41. Bonitati, J.; Elliott, W.B.; Miles, P.G. Interference by carbohydrate and other substances in the estimation of protein with the Folin-Ciocalteu reagent. Anal. Biochem. 1969, 31, 399-404. [CrossRef]

42. Box, J.D. Investigation of the Folin-Ciocalteau phenol reagent for the determination of polyphenolic substances in natural waters. Water Res. 1983, 17, 511-525. [CrossRef]

43. Górnaś, P.; Šne, E.; Siger, A.; Seglina, D. Sea buckthorn (Hippophae rhamnoides L.) leaves as valuable source of lipophilic antioxidants: The effect of harvest time, sex, drying and extraction methods. Ind. Crops Prod. 2014, 60, 1-7. [CrossRef]

44. Huang, D.; Boxin, O.U.; Prior, R.L. The chemistry behind antioxidant capacity assays. J. Agric. Food Chem. 2005, 53, 1841-1856. [CrossRef]

45. Koleva, I.I.; Van Beek, T.A.; Linssen, J.P.H.; De Groot, A.; Evstatieva, L.N. Screening of plant extracts for antioxidant activity: A comparative study on three testing methods. Phytochem. Anal. 2002, 13, 8-17. [CrossRef] [PubMed]

46. Ferrara, L.; Naviglio, D.; Gallo, M. Extraction of bioactive compounds of saffron (Crocus sativus L.) by ultrasound assisted extraction (UAE) and by rapid solid-liquid dynamic extraction (RSLDE). Eur. Sci. J. 2014, 10, 1-13.

47. DellaGreca, M.; Cutillo, F.; D'Abrosca, B.; Fiorentino, A.; Pacifico, S.; Zarrelli, A. Antioxidant and Radical Scavenging Properties of Malva sylvestris. Nat. Prod. Commun. 2009, 4, 893-896. [CrossRef] [PubMed]

48. De Wit, M.; Du Toit, A.; Osthoff, G.; Hugo, A. Antioxidant Content, Capacity and Retention in Fresh and Processed Cactus Pear (Opuntia ficus-indica and O. robusta) Fruit Peels from Different Fruit-Colored Cultivars. Front. Sustain. Food Syst. $2020,4,133$. [CrossRef]

49. Galano, A.; Vargas, R.; Martínez, A. Carotenoids can act as antioxidants by oxidizing the superoxide radical anion. Phys. Chem. Chem. Phys. 2009, 12, 193-200. [CrossRef] [PubMed]

50. Jiménez-Escrig, A.; Jiménez-Jiménez, I.; Sánchez-Moreno, C.; Saura-Calixto, F. Evaluation of free radical scavenging of dietary carotenoids by the stable radical 2,2-diphenyl-1-picrylhydrazyl. J. Sci. Food Agric. 2000, 80, 1686-1690. [CrossRef] 
51. Miraliakbari, H.; Shahidi, F. Antioxidant activity of minor components of tree nut oils. Food Chem. 2008, 111, 421-427. [CrossRef] [PubMed]

52. García-Alonso, M.; De Pascual-Teresa, S.; Santos-Buelga, C.; Rivas-Gonzalo, J.C. Evaluation of the antioxidant properties of fruits. Food Chem. 2004, 84, 13-18. [CrossRef]

53. Palmieri, S.; Pellegrini, M.; Ricci, A.; Compagnone, D.; Lo Sterzo, C. Chemical Composition and Antioxidant Activity of Thyme, Hemp and Coriander Extracts: A Comparison Study of Maceration, Soxhlet, UAE and RSLDE Techniques. Foods 2020, 9 , 1221. [CrossRef] [PubMed]

54. Gallo, M.; Conte, E.; Naviglio, D. Analysis and Comparison of the Antioxidant Component of Portulaca Oleracea Leaves Obtained by Different Solid-Liquid Extraction Techniques. Antioxidants 2017, 6, 64. [CrossRef] [PubMed]

55. Singh, S.V.; Purohit, M.C. Applications of Eco-Friendly Natural Dye on Wool Fibers Using Combination of Natural and Chemical Mordants. Univers. J. Environ. Res. Technol. 2012, 2, 48-55.

56. Zubairu, A.; Mshelia, Y.M. Effects of Selected Mordants on the Application of Natural Dye from Onion Skin (Allium cepa). Sci. Technol. 2015, 5, 26-32.

57. Khan, A.A.; Iqbal, N.; Adeel, S.; Azeem, M.; Batool, F.; Bhatti, I.A. Extraction of natural dye from red calico leaves: Gamma ray assisted improvements in colour strength and fastness properties. Dye. Pigment. 2014, 103, 50-54. [CrossRef] 